\title{
Experimental and Numerical Investigation of the Application of Phase Change Materials in A Simulative Power Batteries Thermal Management System
}

Ziye Ling, Jiajie Chen, Xiaoming Fang, Zhengguo Zhang*, Tao Xu, Xuenong Gao, Shuangfeng Wang

Key Laboratory of Enhanced Heat Transfer and Energy Conservation, the Ministry of Education, School of Chemistry and Chemical Engineering, South China University of Technology, Guangzhou, 510640, China

*Corresponding author, Tel: 8620 87112845, Fax: 8620 87113870, Email: cezhang@scut.edu.cn 


\section{Abstract}

The thermal management systems using EG-based phase change materials(PCMs) can provide power batteries with a proper operating temperature, slow temperature rise rate and uniform temperature distribution. In this study, a systematical investigation on the effects of thermo-physical properties of the used PCMs on the performance of the systems has been conducted . A series of paraffin/expanded graphite(EG) composites have been applied to a simulative battery thermal management system and to find out the PCM with the best thermal properties. The performances of PCMs varying with the kind of paraffin used, the paraffin mass fraction in composites and the packing density of the composites have been compared. It is found that the paraffin with the melting point of $44{ }^{\circ} \mathrm{C}$ offers batteries the best operating temperature. Furthermore, the synergetic effect of the mass fraction of paraffin in the composite PCM and the packing density of the composite in the thermal management system has been studied. The temperature rise can be slowed down by increasing the composites density and the temperature uniformity can be improved by the increase in EG mass fraction and composite density. After cycle tests, the paraffin/EG composite with paraffin mass fraction of $75 \%$ and density of $890 \mathrm{~kg}$ $\mathrm{m}^{-3}$ shows the best thermal management performance. In addition, numerical research with the computational fluid dynamics (CFD) software, FLUENT was also carried out. The numerical results are in a good agreement with the experiment data. 
Key Words: Battery thermal management; Phase change material; Expanded graphite;

Paraffin; CFD 


\section{Introduction}

Transport sector accounts for a significant share of global fossil fuel combustion-related $\mathrm{CO}_{2}$ emission and so urgent is it to replace fossil fuel with high energy density and low greenhouse gas emission substitutes [1]. Electric vehicles (EVs) and hybrid electric vehicles (HEVs), which have high efficiency and nearly zero emissions are likely the best candidates to stand out from the traditional transport tools. Li-ion batteries, with high specific energy and high operating voltage are considered to be the best power sources for EVs/HEVs [2]. However, the overheating of Li-ion batteries gives rise to battery capacity fades [3, 4] or thermal runaways [5], which degrade the battery performances or even possibly trigger potential risks of fire or explosions. It was recommended by Väyrynen [6] that Li-ion batteries be operated within the temperature range $-20^{\circ} \mathrm{C}$ to $60{ }^{\circ} \mathrm{C}$. Pesaran [7] also presented that the best operating temperature for $\mathrm{Li}$-ion batteries ranged between $25{ }^{\circ} \mathrm{C}$ and $40{ }^{\circ} \mathrm{C}$, and the maximum temperature difference in the battery pack should not exceed $5{ }^{\circ} \mathrm{C}$. Therefore, a good thermal management system is essential for Li-ion batteries with the purpose of improving their safety and working life.

Different techniques have been applied to battery thermal management [8-10]. Compared with traditional ways of cooling by forced air and liquid convection, a passive thermal management system using phase change materials (PCMs) shows 
high efficiency and simplicity. Al-Hallaj et al. [11] first proposed to apply PCMs to the battery thermal management system, which can absorbed the heat generated inside batteries by the phase change with large latent heat to keep the temperature in the battery pack within the safety range for a long time. Their further works [12-19] have proved that PCM-based thermal management system have a good temperature control performance. By distributing PCMs into Al-foam [15] or compositing PCMs with EG [13] to improve the thermal conductivity of PCMs, the temperature difference in battery pack could be decreased significantly. There were low capacity fades for batteries under the thermal management of PCMs. Compared with the way of forced air cooling, lower temperature rise and more uniform temperature distribution in the passive thermal management system prevented the contagious thermal runaway[17]. The mostly used PCM in the series of researches was pure RT 42 and RT 42/EG composites with the phase change temperature of $42{ }^{\circ} \mathrm{C}$ and the specific enthalpy of $187 \mathrm{~kJ} \mathrm{~kg}^{-1}$ and $127 \mathrm{~kJ} \mathrm{~kg}^{-1}$. However, these studies used just a single kind of PCM to characterize its temperature control performance and no one examined the performances of battery thermal management using different PCMs to find out the best material.

The EG-based composite PCMs prepared by absorbing organic PCMs into the pores EG, not only retain high specific enthalpy of phase change of paraffin but also integrate with high thermal conductivity of EG $[13,20]$. One can expect that the 5 
EG-based composite PCMs are a suitable kind of form-stable PCMs for passive battery thermal management systems. It is obvious that the temperature control performance of the paraffin/EG composite is significantly influenced by the thermo-physical properties like the phase change temperature, specific enthalpy of phase change, thermal conductivity, which vary with types of PCMs, density of the composites and mass ratio of paraffin over EG. Py et al. [21] and Mills et al. [13] presented that the increasing bulk density of the EG matrix helped increase the thermal conductivity of the composite. Rao [22] and Sari [23] reported that at the cost of the specific enthalpy of phase change, by increasing the EG mass fraction in the composite, the thermal conductivity of the composite PCM was to be improved, leading to a faster battery temperature elevating rate but the higher temperature uniformity.

Therefore, it is necessary to conduct a systematical investigation on the effects of the phase change temperature and mass fraction of the PCM in the composite along with the packing density of the composite on the temperature control performance of an EG-based composite PCM.

In addition, numerical studies on the thermal storage/release process have been carried out. Al-abidi et al. [24] has reviewed the application of computational fluid dynamic (CFD) in modeling the phase change process of PCMs. The enthalpy-based 
numerical approach[25-29] is believed to be reliable and efficient in designing and optimizing the passive battery thermal management system.

In the present study, paraffin/EG composites with different phase change temperature, packing density and mass percentage of paraffin are applied to the thermal management of four heaters that simulate power batteries generating heat. The temperature regulating performance of each composite PCMs is compared to find out the best PCM. We use two parameters to characterize the performance of the PCM: 1. The time for the heater surface temperature to arrive at $60{ }^{\circ} \mathrm{C} ; 2$. The maximum temperature difference in the PCM module. A good thermal management system offers longer duration and lower temperature difference. The comparison of performances of three kinds of paraffin/EG composites with different phase change temperature is conducted first. With the paraffin/EG composite owning the optimal phase change temperature, the effect of its packing density and mass fraction of paraffin, which have a decisive influence on the thermal conductivity and specific enthalpy of phase change will then be discussed in detail. Besides the experiment study, a numerical research via the commercial CFD software FLUENT was also carried out and results of numerical study showed a great agreement with the experiment data. 


\section{Experiment and Simulation}

\subsection{Preparation and characterization of paraffin/EG composite PCMs}

The paraffin/EG composites were prepared by submerging EG into melted paraffin with a designed mass ratio of paraffin over EG. After the PCM had been fully absorbed into EG, cool the composites down to room temperature. To optimize the phase change temperature of the EG-based composite PCMs used in battery thermal management system, three kinds of paraffin with phase change temperature of $36^{\circ} \mathrm{C}$, $44{ }^{\circ} \mathrm{C}$ and $52{ }^{\circ} \mathrm{C}$ were used to prepare the EG-based composite PCMs. As presented by Zhang and Fang [20], the maximum mass fraction of paraffin in the EG-composite is $85.6 \%$. Therefore, the maximum mass percentage selected in this paper is $85 \%$. And the performance of the series of composite PCMs with the paraffin mass fraction of $75 \%$ is used to compare with that of $85 \%$.

The enthalpy of phase change and heat capacity of PCMs were measured by a differential scanning calorimeter (DSC, Q20, TA Instruments Inc) with an average error of $\pm 1.0 \%$. The thermal conductivity was measured by the HOTDISK thermal constants analyzer TPS 2500. Sensor 5464 with the radius $3.189 \mathrm{~mm}$ was sandwiched between two $\Phi 40 \times 10 \mathrm{~mm}$ cylinders made of paraffin/EG composites which had been compacted into the required density. 


\subsection{Simulative power battery thermal management systems}

Figure 1(a) illustrates a schematic diagram of the experimental set-up for the simulative power battery thermal management system. Four heaters $(\underline{\Phi} 18 \times 100 \mathrm{~mm})$ were used for simulating power batteries and arranged axisymmetrically in a stainless steel cylinder $(\underline{\Phi} 108 \times 100 \mathrm{~mm})$ with a thermal insulation layer outside,. The paraffin/EG composites were compacted into remaining space of the cylinder with a certain density ranging from $660 \mathrm{~kg} \mathrm{~m}^{-3}$ to $1040 \mathrm{~kg} \mathrm{~m}^{-3}$. Details of thermal properties of paraffin and system characteristics can be found in Table 1.

Three K-type thermocouples, the position of which is shown in Figure 1(b), were linked to an Agilent 34970A data acquisition unit to monitor the temperature variations of the system. The thermocouple tagged as $1 \#$ was welded at the surface of one heater, and the other two, tagged as 2\# and 3\#, were inserted into the compressed composite PCM. All three thermocouples were placed at the depth of $50 \mathrm{~mm}$ from the top surface. The temperature variation of 1\#, $2 \#$ and $3 \#$ during heating and cooling was recorded. The measurement error of temperature induced by thermo-couples and the instrument was within $1{ }^{\circ} \mathrm{C}$. The duration of keeping the temperature of $1 \#$ under $60{ }^{\circ} \mathrm{C}$ and the temperature difference between $2 \#$ and $3 \#, \Delta \mathrm{T}$, were used to characterize the temperature control performances.

Each System was heated from room temperature to $60{ }^{\circ} \mathrm{C}$ at the power of $5 \mathrm{~W}, 10$ 
$\mathrm{W}$ and $15 \mathrm{~W}$ for each heater, with the corresponding heat density of $196,487 \mathrm{~W} \mathrm{~m}^{-3}$, $392,975 \mathrm{~W} \mathrm{~m}^{-3}$ and $589,463 \mathrm{~W} \mathrm{~m}^{-3}$. The PCMs and heaters were then cooled down to room temperature with the natural convection of air and the cooling time was recorded.

The heating power of heater was determined by ohmic heat equation:

$$
\mathrm{Q}=\frac{U^{2}}{R}
$$

Where Q represents the heat power of each heater, $\mathrm{U}$ is the applied voltage and $\mathrm{R}$ is the electric resistance of each heater. $\mathrm{U}$ and $\mathrm{R}$ was measured by an multimeter with measurement error $\Delta \mathrm{U}$ and $\Delta \mathrm{R}$ of $\pm 1 \mathrm{~V}$ and $\pm 1 \Omega$.

The error of heat generation rate $\Delta \mathrm{Q}$ for each heater was calculated by the transfer function:

$$
\Delta Q=\sqrt{\left(\frac{2 U}{R} \Delta U\right)^{2}+\left(-\frac{U^{2}}{R^{2}} \Delta R\right)^{2}}
$$

$\mathrm{R}$ was kept as constant $973 \Omega$ and $\Delta \mathrm{Q}$ increased from $0.14 \mathrm{~W}$ to $0.25 \mathrm{~W}$ as the applied voltage increased.

\subsection{Simulation}

As Al-abidi [24] summarized, two major methods including the temperature 10 
based and the enthalpy based methods could be used to simulate the melting and solidification process. The enthalpy-based method attracts more attention because of its easiness and has been assembled in some commercial CFD software like FLUENT. In this study, the Melting/Solidification package in CFD software FLUENT which developed from the enthalpy-method was to simulate the temperature elevating curves for batteries with/without the thermal management of PCMs.

Since the heaters positioned axisymmetrically, the computational domain only covered a quarter of the entire set-up. As shown in Figure 1(c), Boundary A was the periodic boundary and Boundary $\mathrm{B}$ was treated as the adiabatic wall. The computational domain was divided into two parts: one was the domain of the heater (the blue area) and the other was the composite PCM wrapping up the heater (the gray area). The interface between the heater and PCM was treated as a coupled wall. Before carrying out the numerical simulation, following assumptions had made for simplicity as following:

(1) The density change due to solid-phase change was negligible;

(2) The specific heat and thermal conductivity of the heaters and PCM were constant;

(3) The heat dissipated through radiation was neglected;

(4) The boundary outside the composite PCM was adiabatic; 
(5) The viscosity of the composite PCM was assumed to be infinity to the magnitude of $10^{5}$ since there was no liquid motion in the form-stable composite.

Based on assumptions above, the energy conservation equation was expressed as follows:

$\rho \frac{\partial H}{\partial t}=k\left(\frac{\partial^{2} T}{\partial x^{2}}+\frac{\partial^{2} T}{\partial y^{2}}+\frac{\partial^{2} T}{\partial z^{2}}\right)+\dot{q}$

$\mathrm{H}=\mathrm{h}+\Delta \mathrm{H}$

$\mathrm{h}=\int_{T_{0}}^{T} c_{p} d T$

$\Delta \mathrm{H}=\beta \gamma$

$\beta= \begin{cases}0 & T<T_{m} \\ 1 & T>T_{m}\end{cases}$

$\Delta \mathrm{H}$ was the enthalpy change during phase change. $\dot{q}$ was the heat source density and only existed in the domain of heaters. $\mathrm{T}_{0}$ was the initial temperature that equals $25^{\circ} \mathrm{C}$.

Momentum conservations were also calculated, but because of the infinite viscosity described in assumption 5, the velocities in all directions were zero. The thermal conduction was the only way to transfer heat. 
The initial and boundary conditions were as follows:

The initial condition:

$\mathrm{t}=0, \mathrm{~T}(\mathrm{x}, \mathrm{y}, \mathrm{z})=T_{0}$

At boundary of the heater

$-k_{h} \frac{\partial T_{h}}{\partial n}=-k_{P C M} \frac{\partial T_{P C M}}{\partial n}$

Where $\mathrm{n}$ directed to the normal direction.

Outside PCM

$-k_{P C M} \frac{\partial T_{P C M}}{\partial n}=0$

At the symmetry surface

$$
-k_{P C M} \frac{\partial T_{P C M}}{\partial n}=0
$$

The governing equations were solved through the Finite Element Method combining with these boundary and initial conditions.

Mesh was generated by Gambit, the pre-processing software packaged in FLUENT 6.3. The mesh dependence were tested at the first. After a careful analysis of the mesh number effects, 24633 was chosen as the total grid number. The time step 
dependence test was also conducted and it was found that it's reliable if the temperature data was exported every $10 \mathrm{~s}$. The value of the time step was much bigger than other researchers used [30]. Usually a very small time step was required when the melting/solidification process was simulated for PCMs to monitor the flow motion of the melted PCM. However, in the current work, the form-stable paraffin/EG composite was used as the PCM and no liquid flow occurred during heating or cooling. The only way of exchanging heat between the heater and PCM was heat conduction. So there was no need of a very small time step to capture the flow motion of liquid paraffin, which saved a lot of time. The parameters to take care of the flow motion in the solution method and solution control retained as default, with the second-order upwind difference scheme for energy and the first order implicit transient formulation. The residual for energy was set to $10^{-8}$ to make sure the convergence of energy equation.

\section{Result and discussion}

\subsection{Effect of phase change temperature}

Figure 2(a) shows the temperature elevating curves of 1\# in PCMs with different phase change temperature $36^{\circ} \mathrm{C}, 44^{\circ} \mathrm{C}$ and $52^{\circ} \mathrm{C}$ at the power of $5 \mathrm{~W}$. In the system without PCMs, it takes $390 \mathrm{~s}$ for heater temperature to rise above $60{ }^{\circ} \mathrm{C}$ at the power of 5W. However, with the thermal management of PCMs, the duration of keeping 
heater temperature under $60{ }^{\circ} \mathrm{C}$ has been increased to around $8000 \mathrm{~s}$, which is a significant improvement.

The temperature elevating curve in systems with PCMs can be divided into three parts: The temperature rises rapidly if it is below or above the phase change temperature and the temperature rises slowly if it falls within the phase change temperature range, as the heat is absorbed by the composite PCMs as latent heat.

The batteries are recommended to work between $25{ }^{\circ} \mathrm{C}$ and $50{ }^{\circ} \mathrm{C}$, hence the phase change temperature of PCM should fall within this range. As indicated by Ramadass [3], when the operating temperature was over $50{ }^{\circ} \mathrm{C}$, the capacity fade of Li-ion battery could be $70 \%$ after 490 cycles, while the loss was just $36 \%$ after 800 cycles when the operating temperature was $45{ }^{\circ} \mathrm{C}$. As the major operating temperature range provided by the paraffin with melting point of $52{ }^{\circ} \mathrm{C}$ is over $50^{\circ} \mathrm{C}$, this kind of PCM fails to meet the requirement and PCMs with lower phase change temperature is preferred. However, if the phase change temperature is lower than the ambient temperature, PCMs would melt before the batteries work and the latent heat is wasted. Moreover, low phase change temperature hinders the system from cooling down quickly. Figure 2(b) shows the cooling curve under natural convection in the PCMs with different phase change temperature. It takes 15780 s, 13650s and 9890 s for the heaters to cool down to $30{ }^{\circ} \mathrm{C}$ in the PCMs with melting point of $36{ }^{\circ} \mathrm{C}, 44{ }^{\circ} \mathrm{C}$ and 52 
${ }^{\circ} \mathrm{C}$, respectively. Because of the low temperature difference between the system and environment, it takes much longer for the PCMs with low phase change temperature of $36^{\circ} \mathrm{C}$ to cool down. The temperature range between $40{ }^{\circ} \mathrm{C}$ and $45^{\circ} \mathrm{C}$ is neither too high nor too low and the composite PCM with melting point of $44{ }^{\circ} \mathrm{C}$ is recommended for the battery thermal management. The following tests were all carried out with the composite PCM with the melting point of $44^{\circ} \mathrm{C}$.

\subsection{Effects of packing density and paraffin mass fraction of the composite PCMs}

Figure 3(a c) illustrate the temperature rise curves of the surface of the heaters in the composite PCMs with the paraffin percentage of $75 \%$ at different packing density. It is obvious that with the increase of packing density, the moment heater temperature to reach $60{ }^{\circ} \mathrm{C}$ is postponed. In a fixed volume, the composite PCM with higher density provides higher heat capacity, both in sensible and latent heat. Therefore, much slower rise rate is observed for the composite PCM with high density.

The temperature difference between $2 \#$ and $3 \#, \Delta \mathrm{T}$, is chose to characterize the temperature uniformity of the thermal management system since it is nearly the maximum temperature difference in the compact PCM module. The temperature uniformity of a battery pack is highly affected by the thermal conductivity of PCM 
module, which increases with the packing density.

For the composite PCMs with paraffin mass fraction of $75 \%$, as Figure 3(e f) illustrated, smaller temperature difference could be observed in the system with higher density PCMs, especially at a high heat generation rate. If the packing density increases from $796 \mathrm{~kg} \mathrm{~m}^{-3}$ to $1040 \mathrm{~kg} \mathrm{~m}^{-3}$, the average $\Delta \mathrm{T}$ decreases from $0.6{ }^{\circ} \mathrm{C}$ to $0.3{ }^{\circ} \mathrm{C}$ at the power of $5 \mathrm{~W}$, while at the power of $15 \mathrm{~W}$, the average $\Delta \mathrm{T}$ drops from $1.8^{\circ} \mathrm{C}$ to $0.5{ }^{\circ} \mathrm{C}$. High thermal conductivity insures high rate of the removal of heat which is extremely crucial when facing a very high heat density.

Similar trend can be found for the series of composite PCMs with paraffin mass fraction of $85 \%$, as shown in Figure 4.

It is interesting that a peak for $\Delta \mathrm{T}$ appears at a specific time point. At the initial state, there is no temperature difference between $2 \#$ and $3 \#$. As the heater started to generate heat, a temperature difference occurs to drive the heat from heaters to PCMs. The temperature point near heaters (e.g. 2\#) is higher than the point far away from heaters (e.g. 3\#). After a period, the temperature difference steps into relatively stable state. As the temperature continues to rise, the PCM melts when the temperature meats the phase change temperature. At a certain point, the PCM at 2\# has fully melted and the PCM at 3\# begins to melt. Since there is a small temperature variation during melting, the temperature of $3 \#$ is assumed a constant while the temperature of 
2\# keeps rising, leading to a sharp rise in the $\Delta \mathrm{T}$. After the PCM at $3 \#$ fully melts, the temperature of $3 \#$ rises again and $\Delta \mathrm{T}$ drops down. That is the reason why there is a peak for $\Delta \mathrm{T}$.

However, high level of compacting would impair the porosity of EG matrix and squeeze the paraffin out from the EG matrix. The leakage might raise a lot of problems during the cycles of heat absorption/desorption and extra sealing techniques are needed. After three thermal cycles, $2 \%$ and $1.2 \%$ mass loss of paraffin were observed in System 5 with a density of $919 \mathrm{~kg} \mathrm{~m}^{-3}$ and System 8 with a density of $1040 \mathrm{~kg} \mathrm{~m}^{-3}$ and further leakage would be observed if the cycles continue. Taking the leakage of paraffin into account, excessively compact composite PCMs should be avoided and $850 \mathrm{~kg} \mathrm{~m}^{-3}$ and $920 \mathrm{~kg} \mathrm{~m}^{-3}$ are recommended as the best density for paraffin/EG composites with the paraffin percentage of $85 \%$ and $75 \%$.

Contribution of paraffin mass proportion to thermo-physical properties is more complicated. High paraffin mass fraction offers high specific enthalpy of phase change, while decreasing the graphite ratio lower the thermal conductivity of the composites, as reflected in Table 1 . Therefore, it is commonly agreed that the composite PCM of high paraffin mass fraction shows better performance in temperature rise control but poorer in temperature uniformity.

True is it when the density is the same. However, the poorer temperature rise 18 
control performance of the composite with low paraffin mass fraction could be overcome if it is compacted into higher density.

Comparing System 4 with System 7, the composite PCM in System 7 has lower paraffin mass fraction but higher density. The total latent heat in System 4 and System 7 are $65.4 \mathrm{~kJ}$ and $62.7 \mathrm{~kJ}$ and the thermal conductivity is $7.5 \mathrm{~W} \mathrm{~m}^{-1} \mathrm{~K}^{-1}$ and $11.2 \mathrm{~W} \mathrm{~m}^{-1}$ $\mathrm{K}^{-1}$, respectively. The thermal conductivity in System 7 is higher but the total latent heat is not much lower. Traditionally, as the mass fraction of paraffin is the only variable considered, it is suggested that System 7 would show a better performance in temperature uniformity control but poorer in temperature rise control. In the current study, we take both the mass fraction of paraffin and the composite density into account and the result shows different from the previous conclusion. As shown in Figure 5(b), the temperature distribution in System 7 is much more uniform than System 4, which is in agreement with previous results. However, there is a narrow difference in the working duration of PCMs between System 4 and System 7. As shown in Figure 5(a), it takes the heater temperature in System 7 for 8830 s, 3850 s and $2420 \mathrm{~s}$ to rise above $60{ }^{\circ} \mathrm{C}$ at the power of $5 \mathrm{~W}, 10 \mathrm{~W}$ and $15 \mathrm{~W}$, compared with the time of 8730 s, $3820 \mathrm{~s}$ and $2180 \mathrm{~s}$ in System 4. The working duration in System 7 is even a little superior to System 4. The high density increases the the unit volumetric enthalpy of phase change for the PCMs with lower paraffin ratio, which improves the temperature rise control performance. Besides, the high thermal conductivity is also a 
key factor to slow down the temperature rise. The high thermal conductivity accelerates the heat conduction rate and lower the temperature difference between the heater and PCM. Even the total latent heat in System 7 is lower than that in System 4, the temperature in System 7 is kept under $60{ }^{\circ} \mathrm{C}$ for longer..

If heat generation rate is as low as $200,000 \mathrm{~W} \mathrm{~m}^{-3}$ ( $5 \mathrm{~W}$ per heater), there is no remarkable difference of $\Delta \mathrm{T}$ between System 4 and System 7, as shown in Figure 5(b). However, as the heat density increased, a bigger temperature difference between heaters and PCMs is required to conduct the heat. The PCM with a higher thermal conductivity could effectively lower the difference. If the heat density exceeds $400,000 \mathrm{~W} \mathrm{~m}^{-3}$ (10W per heater), the $\Delta \mathrm{T}$ in System 7 is obviously lower than System 4, which means in System 7, there is a much more uniform temperature distribution. As Yan et al. [31] predicted, the heat density of battery under $10 \mathrm{C}$ discharge rate could exceed $1,000,000 \mathrm{~W} \mathrm{~m}^{-3}$. The composites with low paraffin ratio but high density is definite to attract considerable attention.

Therefore, the paraffin/EG composite with a density of $890 \mathrm{~kg} \mathrm{~m}^{-3}$ and the paraffin mass fraction of $75 \%$ is recommended as the PCM used in power battery thermal management. 


\subsection{Simulation and experiment comparison}

Figure 6(a) compares the temperature variation of $1 \#$ of simulation with experiment data, in the system without PCM. Figure 6(b) and Figure 6(c) compares temperature curve of 1\# and 2\# in System 7.

As shown in Figure 6(a), the heater temperature obtained from simulation, rises faster than experiment and the deviation is more obvious as the heating power increased. The difference is probably caused by the difference between the real heating power and the value calculated through Equation (1). As analyzed above, the deviation of heat density, ranging from $0.14 \mathrm{~W}$ to $0.25 \mathrm{~W}$, increased with the applied voltage. So the power used in simulation is possibly higher than experiment and a bigger difference occurs as heat power increases, which brings the faster temperature elevation in simulation.

Figure 6(b) and Figure 6(c) compare the temperature variation obtained from experiment and simulation in System 7. For numerical study, it takes 210 s, 410 s and $630 \mathrm{~s}$ longer for the PCM to fully melt at the power of $15 \mathrm{~W}, 10 \mathrm{~W}$ and $5 \mathrm{~W}$. However, temperature rises more rapidly than experiment, when the temperature is over the melting point of PCM.

The measurement errors of the heat capacity and enthalpy of phase change of PCMs possibly contributes to the longer duration to melt. The measured enthalpy of 
phase change and heat capacity might be larger than the real value. In fact, a $1 \mathrm{~J} \mathrm{~g}^{-1}$ deviation in the enthalpy of phase change could lead to a $50 \mathrm{~s}$ error for the time to melt at the power of $15 \mathrm{~W}$. $\mathrm{T} 0.1 \mathrm{~J} \mathrm{~g}^{-1} \mathrm{~K}^{-1}$ difference in heat capacity could lead to a $140 \mathrm{~s}$ error for a $30{ }^{\circ} \mathrm{C}$ rise at the power of $15 \mathrm{~W}$ with $720 \mathrm{~g}$ PCM.

There are two factors leading to the sharper temperature rise rate for simulation.

One is the higher heat power than real power used in simulation as discussed at the beginning of this section.

Another factor is the heat loss from the system to the environment in experiment. In the experiment, a layer of thermal insulated material covered the external surface of the PCM and the heat loss was neglected in simulation. However, it is impossible to build a fully adiabatic wall and the heat transfer between the system and the ambient actually slower the temperature rise. The heat exchange rate between PCM module and the ambient is decided by the temperature difference between the system and the ambient. At the beginning, the difference was small and there was a low heat loss. As time elapsed, however, the temperature difference became bigger and more heat lost. The longer time it takes, the more heat is lost. Therefore, compared with simulation, the temperature rises slower in experiment, especially when temperature is over the melting point. 
Even though there is a deviation between numerical results and experiment data, simulation results show a considerable agreement with experiment data. Comparisons of results in other systems also support that numerical results are reliable. Numerical calculation is a useful tool to design and optimize battery thermal management thanks to the high efficiency and accuracy. In current study, thermo-physical properties were regarded as constant. But in following works, temperature-dependent properties such as temperature-dependent thermal conductivity and specific heat should be considered to improve the accuracy of simulation.

\section{Conclusion}

In this paper, performances of passive battery thermal management systems using paraffin/EG composites were evaluated. Influences of phase change temperature, composite density and paraffin mass fraction of the composite PCMs were discussed.

The composite PCMs with either too high or too low phase change temperature are not suitable for the battery thermal management system. The composite with medium phase change temperature range between $40{ }^{\circ} \mathrm{C}$ and $45^{\circ} \mathrm{C}$ is recommended. Paraffin/EG composites with high density provide not only a high thermal conductivity, but also the high latent heat in a fixed volume. Increasing the density is to improve the performances both in temperature rise and temperature uniformity control. 
Composites with low paraffin mass fraction have relatively low specific enthalpy of phase change but high thermal conductivity. If compacted into high density, the thermal conductivity and unit volumetric enthalpy of phase change is to be improved and the temperature control performance is much superior to the PCM with high paraffin percentage but low density. The paraffin/EG composite with a density of 890 $\mathrm{kg} \mathrm{m}^{-3}$ and the paraffin mass fraction of $75 \%$ is recommended to be used in power battery thermal management.

Numerical calculation was also carried out. With accurate thermo-physical properties, numerical results show a good agreement with the experiment data.

To summarize, the passive thermal management system using PCMs is powerful for batteries temperature control, both in the control of temperature rise and uniformity. Thermo-physical properties of composites like specific enthalpy of phase change and thermal conductivity, have great influences on the temperature regulation. Expanding the database of thermo-physical properties of PCM/EG composite and combining numerical method are the keys to design an effective passive thermal management system.

\section{Acknowledgement}

This work was supported by the Industry-University-Research Cooperation 
Project of Guangdong Province and Chinese Education Ministry (2012B091100142), the Joint Project of JST-MOST ( 2013DFG60080) and the Joint Funds of NSFC-Guangdong of China (U0934005) 


\section{References}

[1] OECD/ITF. Reducing Transport Greenhouse Gas Emissions. Trends and Data:2010. 2010.

[2] Scrosati B, Garche J. Lithium batteries: Status, prospects and future. Journal of Power Sources. 2010;195:2419-30.

[3] Ramadass P, Haran B, White R, Popov BN. Capacity fade of Sony 18650 cells cycled at elevated temperatures: Part I. Cycling performance. Journal of Power Sources. 2002;112:606-13.

[4] Yuksel T, Michalek J. Development of a Simulation Model to Analyze the Effect of Thermal Management on Battery Life. SAE Technical Paper. 2012:01-0671.

[5] Wang Q, Ping P, Zhao X, Chu G, Sun J, Chen C. Thermal runaway caused fire and explosion of lithium ion battery. Journal of Power Sources. 2012;208:210-24.

[6] Väyrynen A, Salminen J. Lithium ion battery production. The Journal of Chemical Thermodynamics. 2012;46:80-5.

[7] Pesaran AA. Battery thermal models for hybrid vehicle simulations. Journal of Power Sources. 2002;110:377-82.

[8] Zolot MD, Kelly K, Keyser M, Mihalic M, Pesaran A, Hieronymus A. Thermal evaluation of the Honda insight battery pack. INTERSOCIETY ENERGY CONVERSION ENGINEERING CONFERENCE: SAE; 1999; 2001. p. 923-8.

[9] Zolot M, Pesaran A, Mihalic M. Thermal Evaluation of Toyota Prius Battery Pack. FutureCar Conference2002. p. 01-1962.

[10] Pesaran AA. Battery Thermal Management In Ev And Hevs: Issues And Solutions. Battery Man. 2001;43:34-49.

[11] Al-Hallaj S, Selman JR. Thermal modeling of secondary lithium batteries for electric vehicle/hybrid electric vehicle applications. Journal of Power Sources. 2002;110:341-8.

[12] Mills A, Al-Hallaj S. Simulation of passive thermal management system for lithium-ion battery packs. Journal of Power Sources. 2005;141:307-15.

[13] Mills A, Farid M, Selman JR, Al-Hallaj S. Thermal conductivity enhancement of phase change materials using a graphite matrix. Applied Thermal Engineering. 2006;26:1652-61.

[14] Khateeb SA, Farid MM, Selman JR, Al-Hallaj S. Design and simulation of a lithium-ion battery with a phase change material thermal management system for an electric scooter. Journal of Power Sources. 2004;128:292-307.

[15] Khateeb SA, Amiruddin S, Farid M, Selman JR, Al-Hallaj S. Thermal management of Li-ion battery with phase change material for electric scooters: experimental validation. Journal of Power Sources. 2005;142:345-53.

[16] Kizilel R, Lateef A, Sabbah R, Farid MM, Selman JR, Al-Hallaj S. Passive control of temperature excursion and uniformity in high-energy Li-ion battery packs at high current and ambient temperature. Journal of Power Sources. 2008;183:370-5.

[17] Kizilel R, Sabbah R, Selman JR, Al-Hallaj S. An alternative cooling system to enhance the safety of Li-ion battery packs. Journal of Power Sources. 2009;194:1105-12.

[18] Al-Hallaj S, Kizilel R, Lateef A, Sabbah R, Farid M, Selman JR. Passive thermal management using 26 
phase change material (PCM) for EV and HEV Li- ion batteries. Vehicle Power and Propulsion, 2005 IEEE Conference2005. p. 5 pp.

[19] Al-Hallaj S, Khateeb SA, Amiruddin S, Farid M, Selman JR. Thermal management of Li-ion battery with phase change material for electric scooters: experimental validation. Journal of Power Sources. 2005;142:345-53.

[20] Zhang ZG, Fang XM. Study on paraffin/expanded graphite composite phase change thermal energy storage material. Energ Convers Manage. 2006;47:303-10.

[21] Py X, Olives R, Mauran S. Paraffin/porous-graphite-matrix composite as a high and constant power thermal storage material. International Journal of Heat and Mass Transfer. 2001;44:2727-37.

[22] Rao Z, Wang S, Zhang G. Simulation and experiment of thermal energy management with phase change material for ageing LiFePO4 power battery. Energy Conversion and Management. 2011;52:3408-14.

[23] Sarı A, Karaipekli A. Thermal conductivity and latent heat thermal energy storage characteristics of paraffin/expanded graphite composite as phase change material. Applied Thermal Engineering. 2007;27:1271-7.

[24] Al-abidi AA, Bin Mat S, Sopian K, Sulaiman M, Mohammed AT. CFD applications for latent heat thermal energy storage: a review. Renewable and Sustainable Energy Reviews. 2013;20:353-63.

[25] Esen M, Ayhan T. Development of a model compatible with solar assisted cylindrical energy storage tank and variation of stored energy with time for different phase change materials. Energy Conversion and Management. 1996;37:1775-85.

[26] Esen M, Durmuş A, Durmuş A. Geometric design of solar-aided latent heat store depending on various parameters and phase change materials. Solar Energy. 1998;62:19-28.

[27] Esen M. Thermal performance of a solar-aided latent heat store used for space heating by heat pump. Solar Energy. 2000;69:15-25.

[28] $\operatorname{Trp}$ A. An experimental and numerical investigation of heat transfer during technical grade paraffin melting and solidification in a shell-and-tube latent thermal energy storage unit. Solar Energy. 2005;79:648-60.

[29] Jian-you L. Numerical and experimental investigation for heat transfer in triplex concentric tube with phase change material for thermal energy storage. Solar Energy. 2008;82:977-85.

[30] Shatikian V, Ziskind G, Letan R. Numerical investigation of a PCM-based heat sink with internal fins: Constant heat flux. International Journal of Heat and Mass Transfer. 2008;51:1488-93.

[31] Yan B, Lim C, Yin L, Zhu L. Simulation of heat generation in a reconstructed LiCoO2 cathode during galvanostatic discharge. Electrochimica Acta. 2013;100:171-9. 


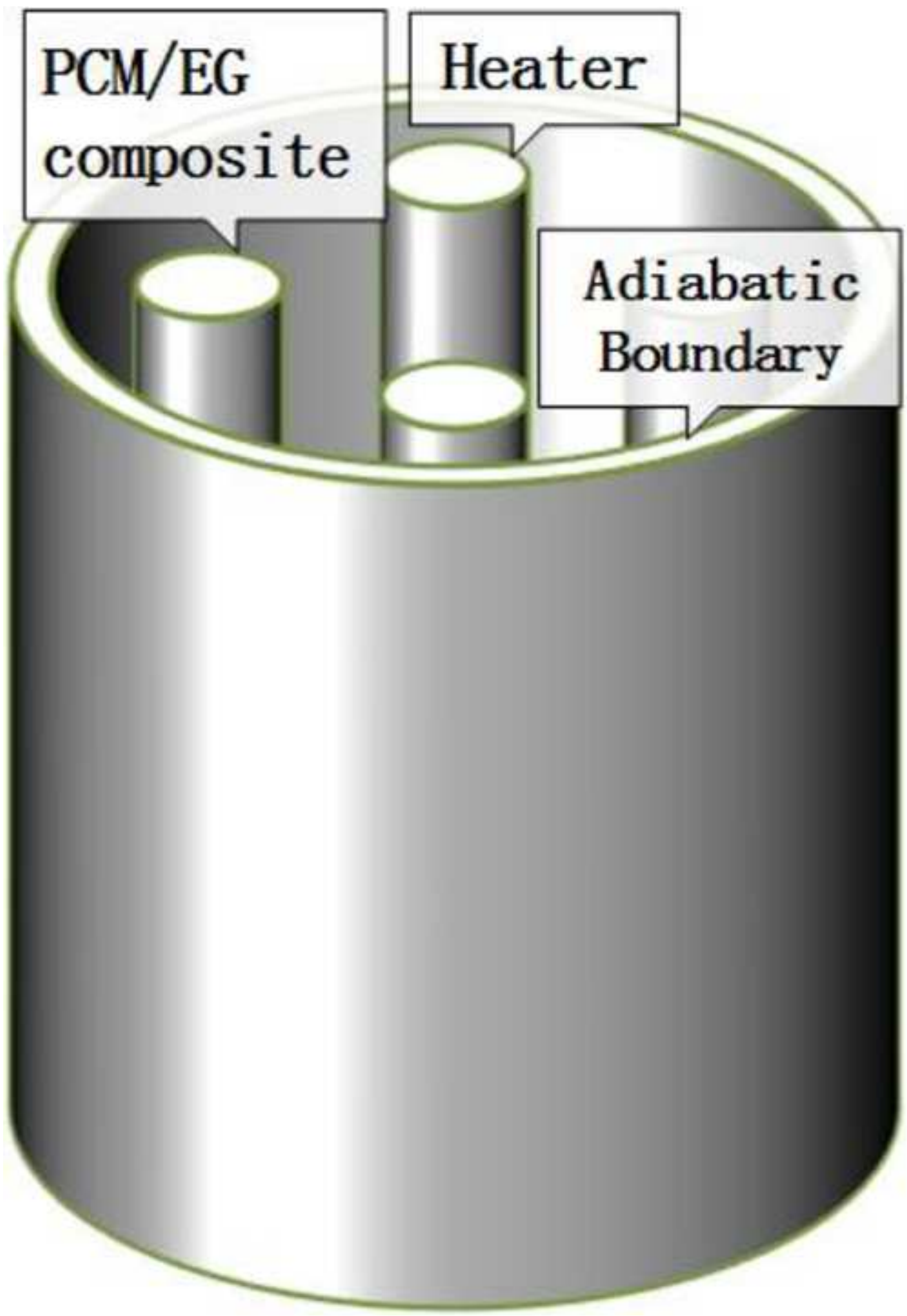


Figure 1b

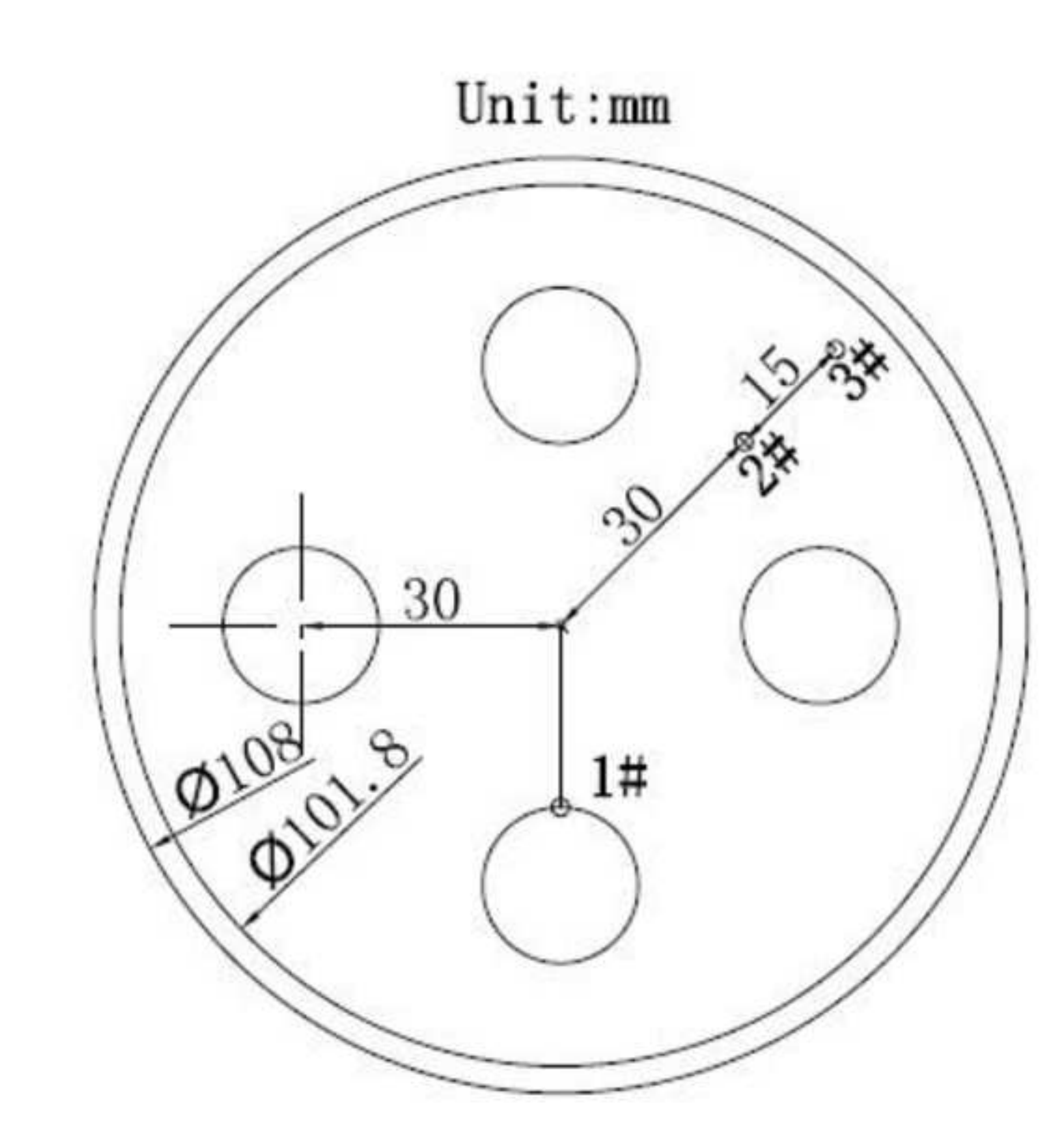

Po

Figure
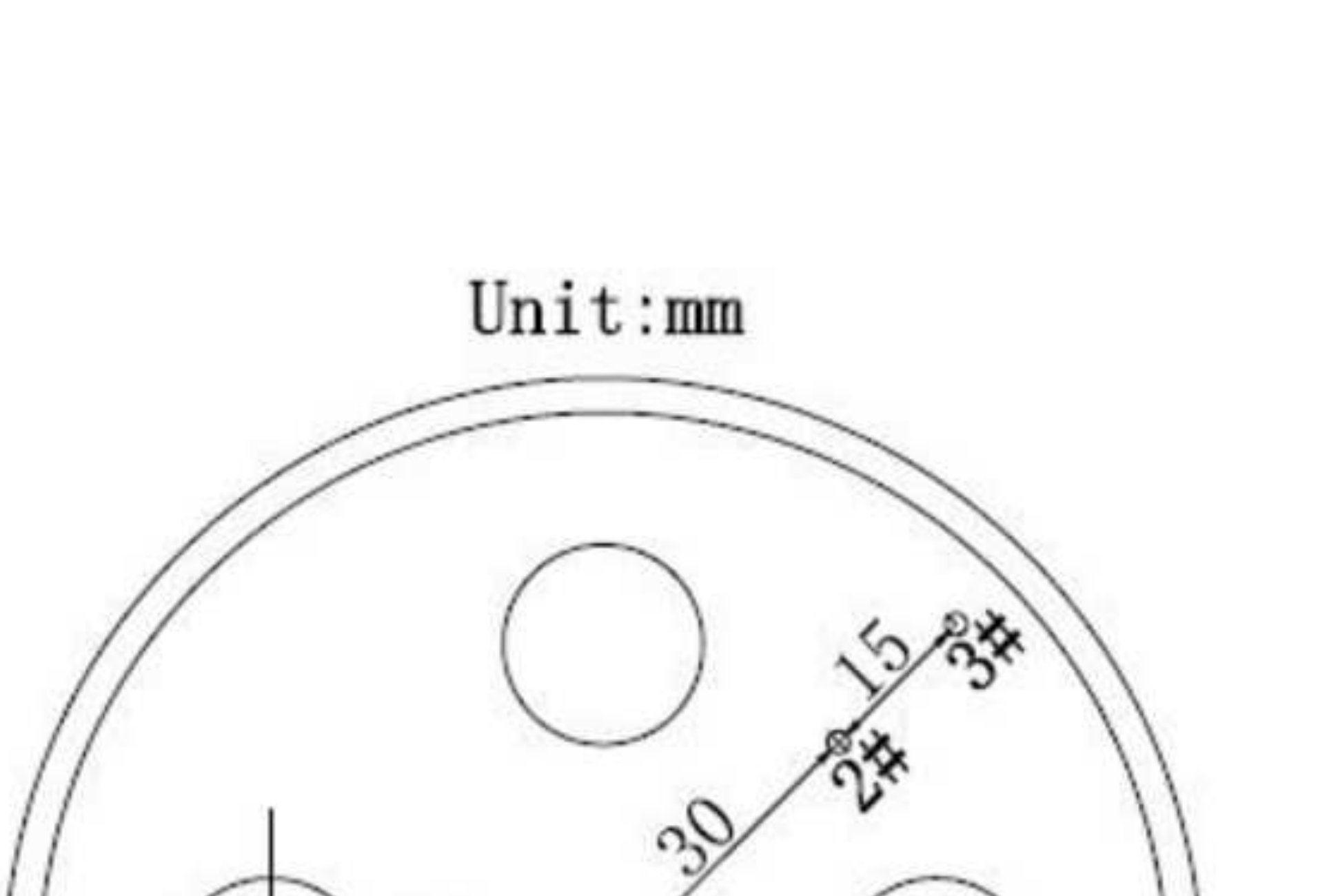
更 tor

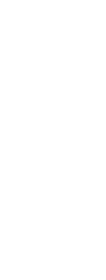




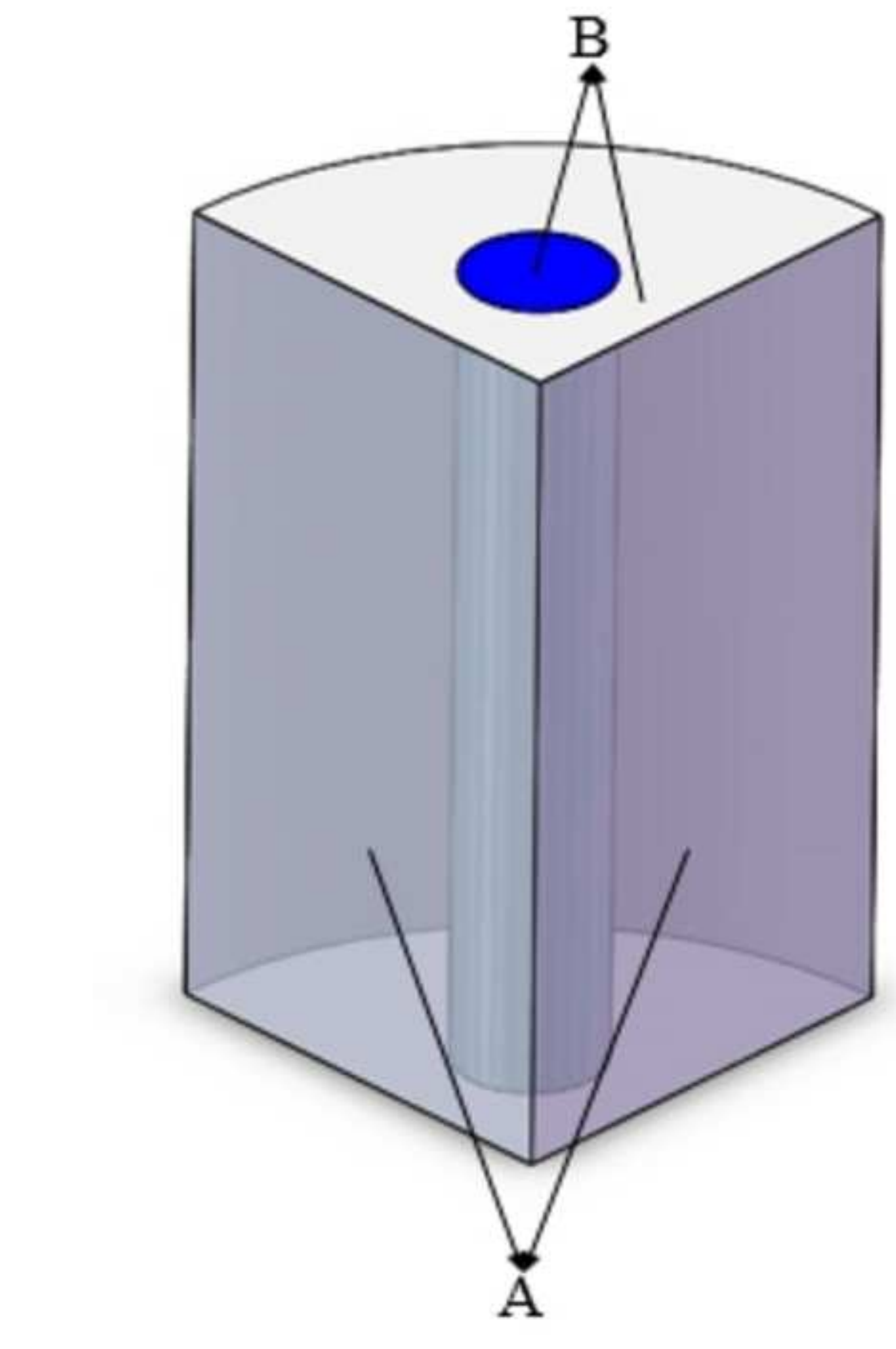

Figure 1c

Fic
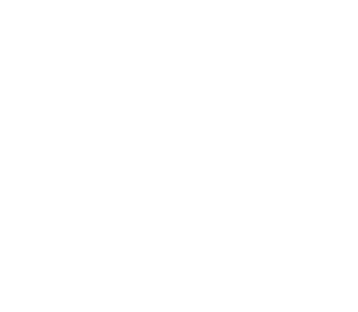


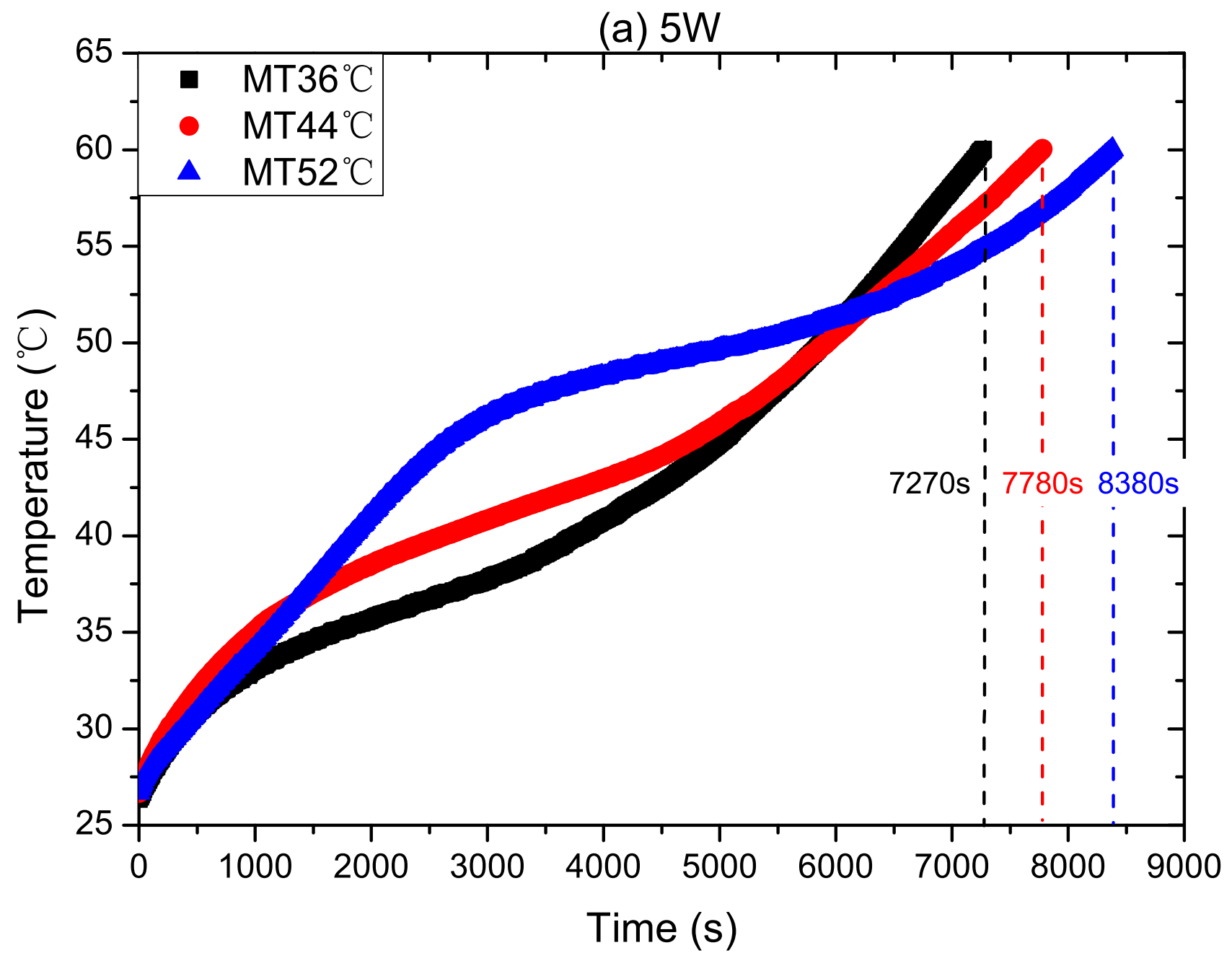




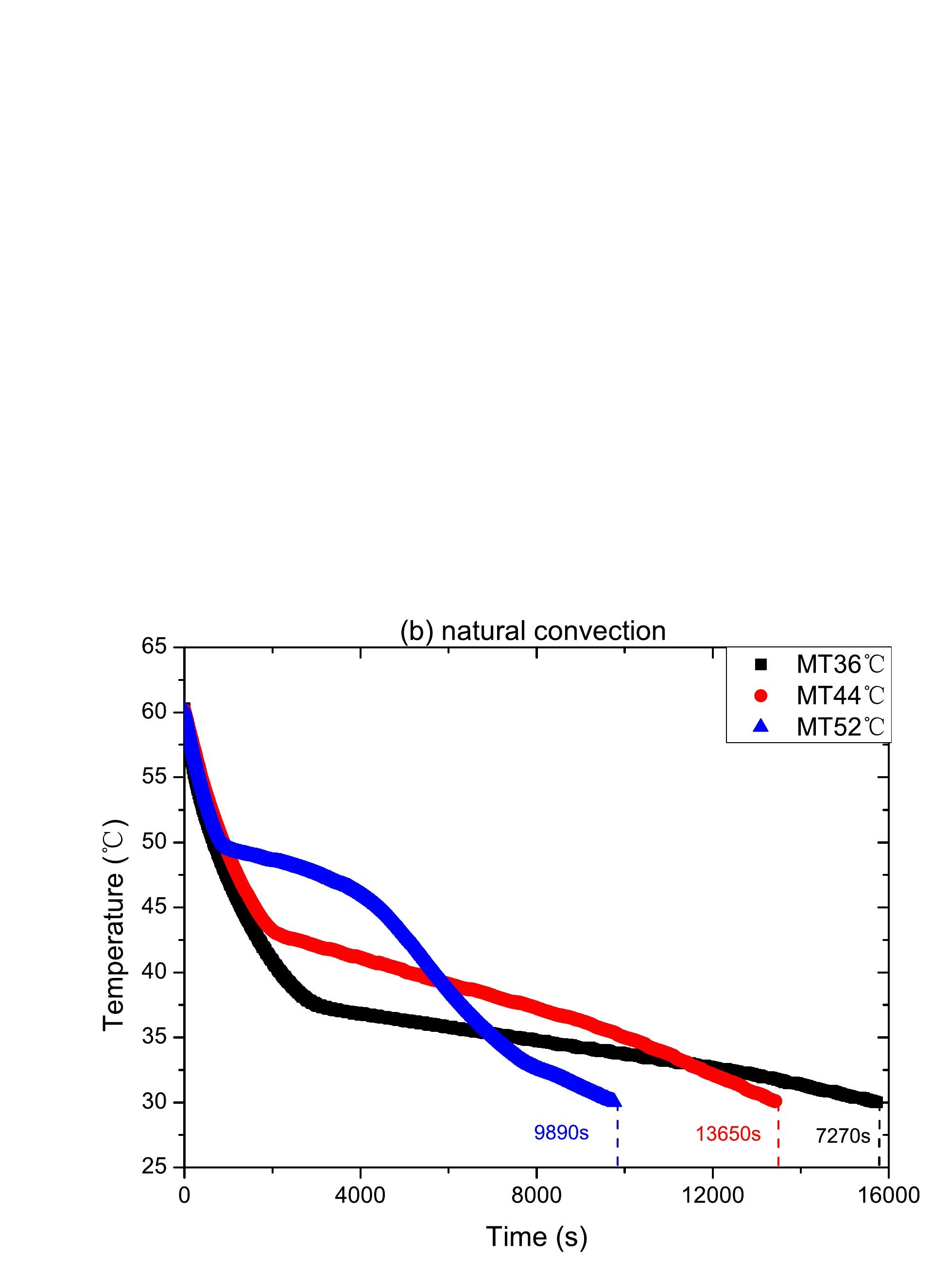

Figure 2b

Figure $2 b$ 


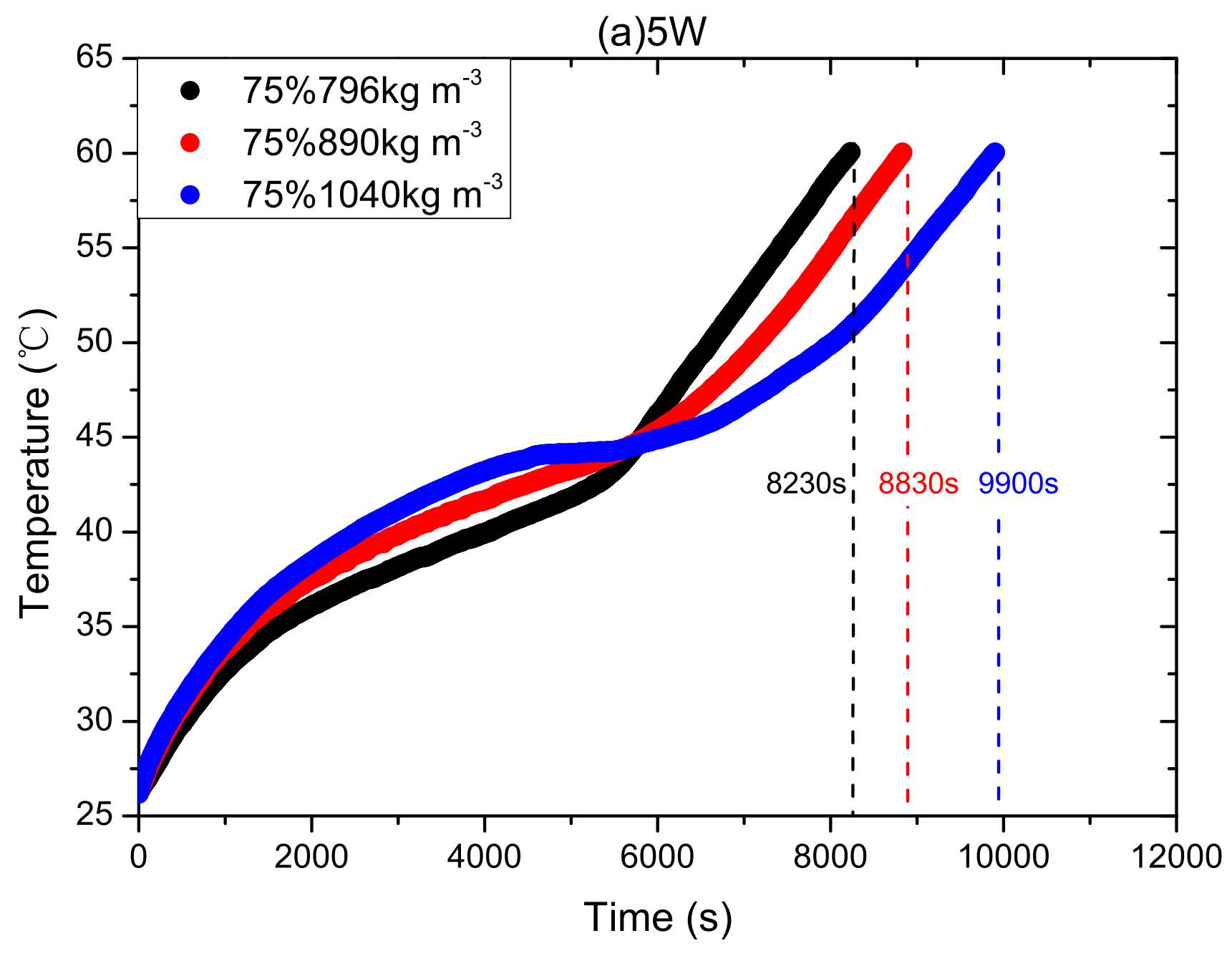




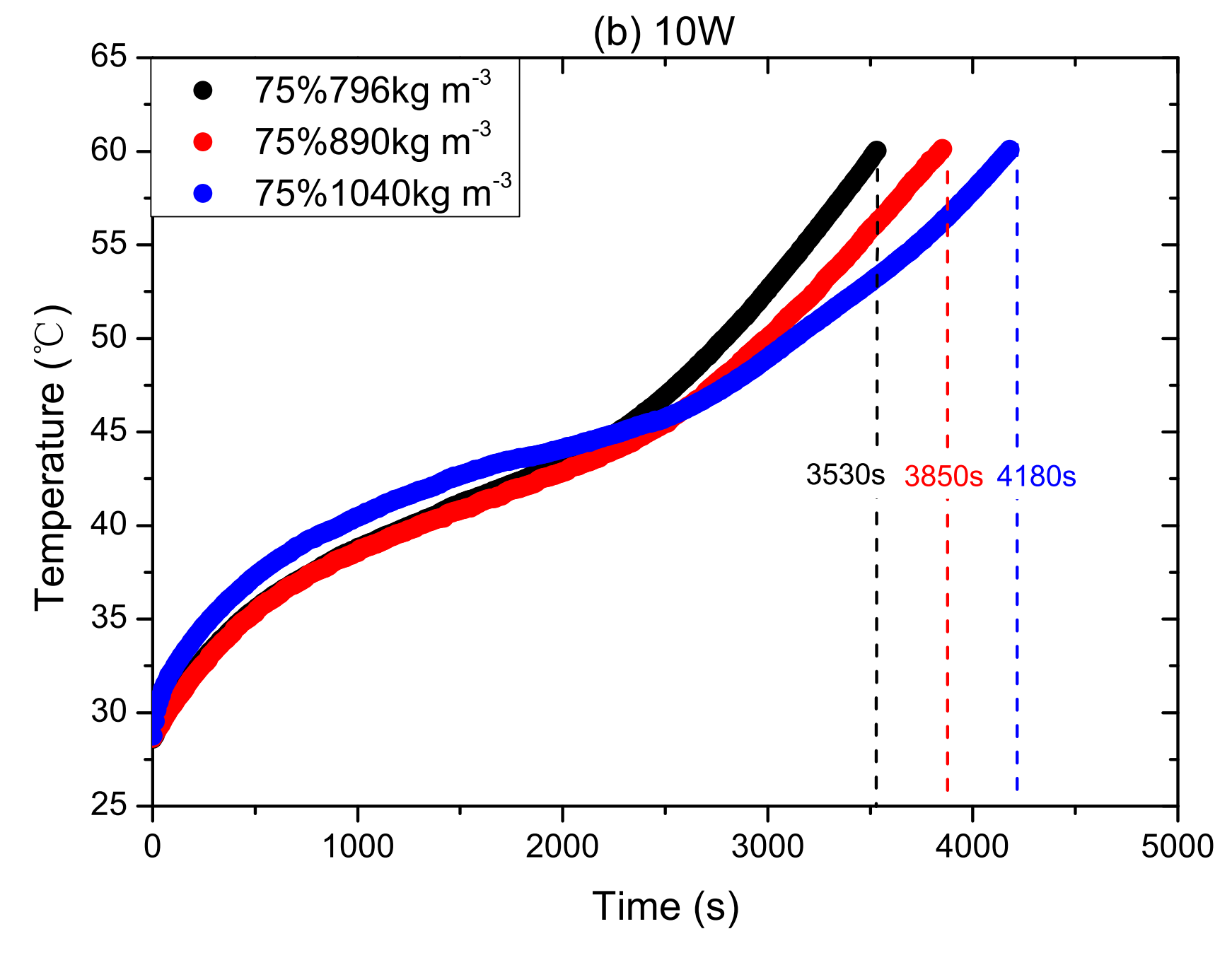

Figure $3 b$ 


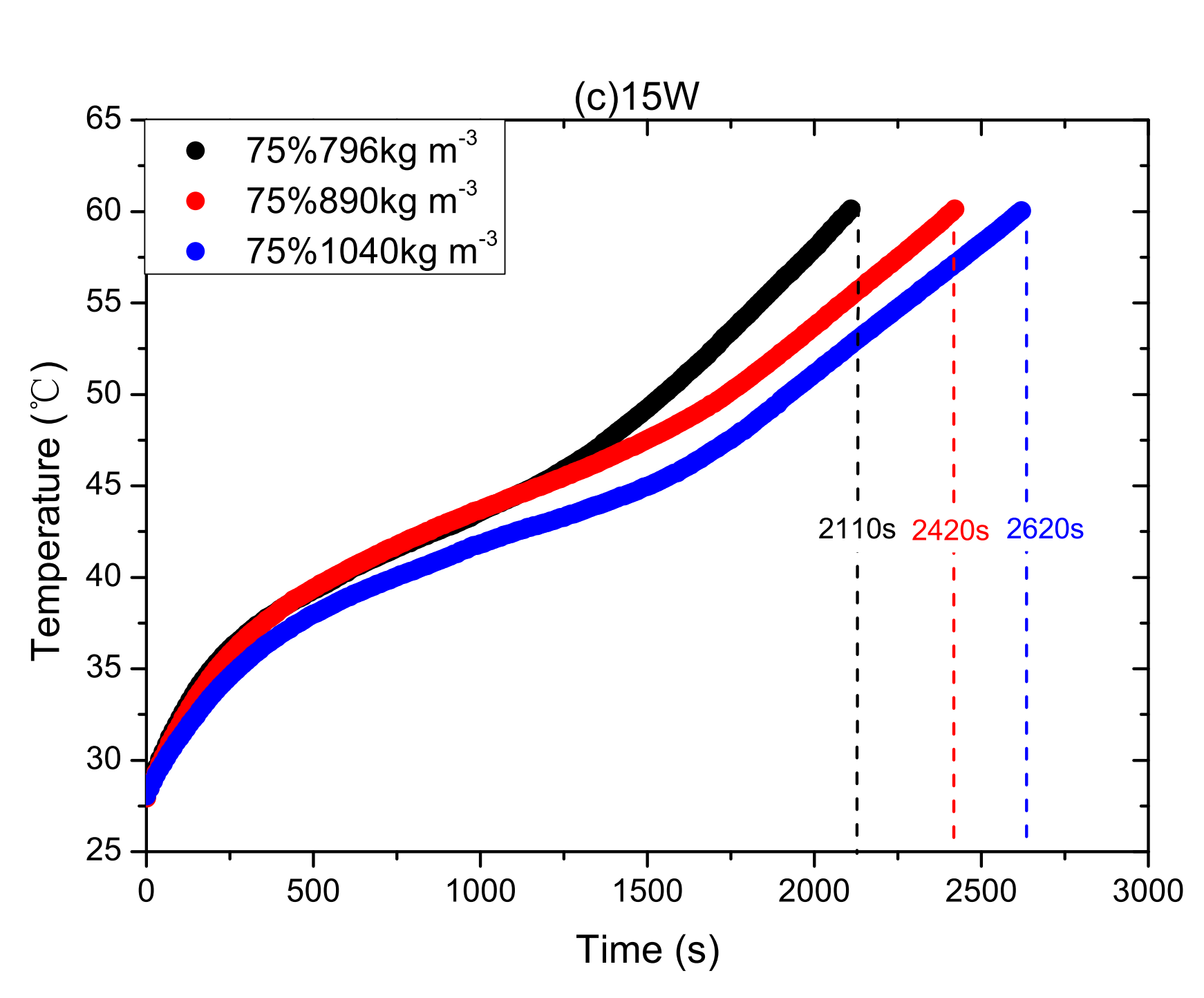

Figure 3c

(2) 


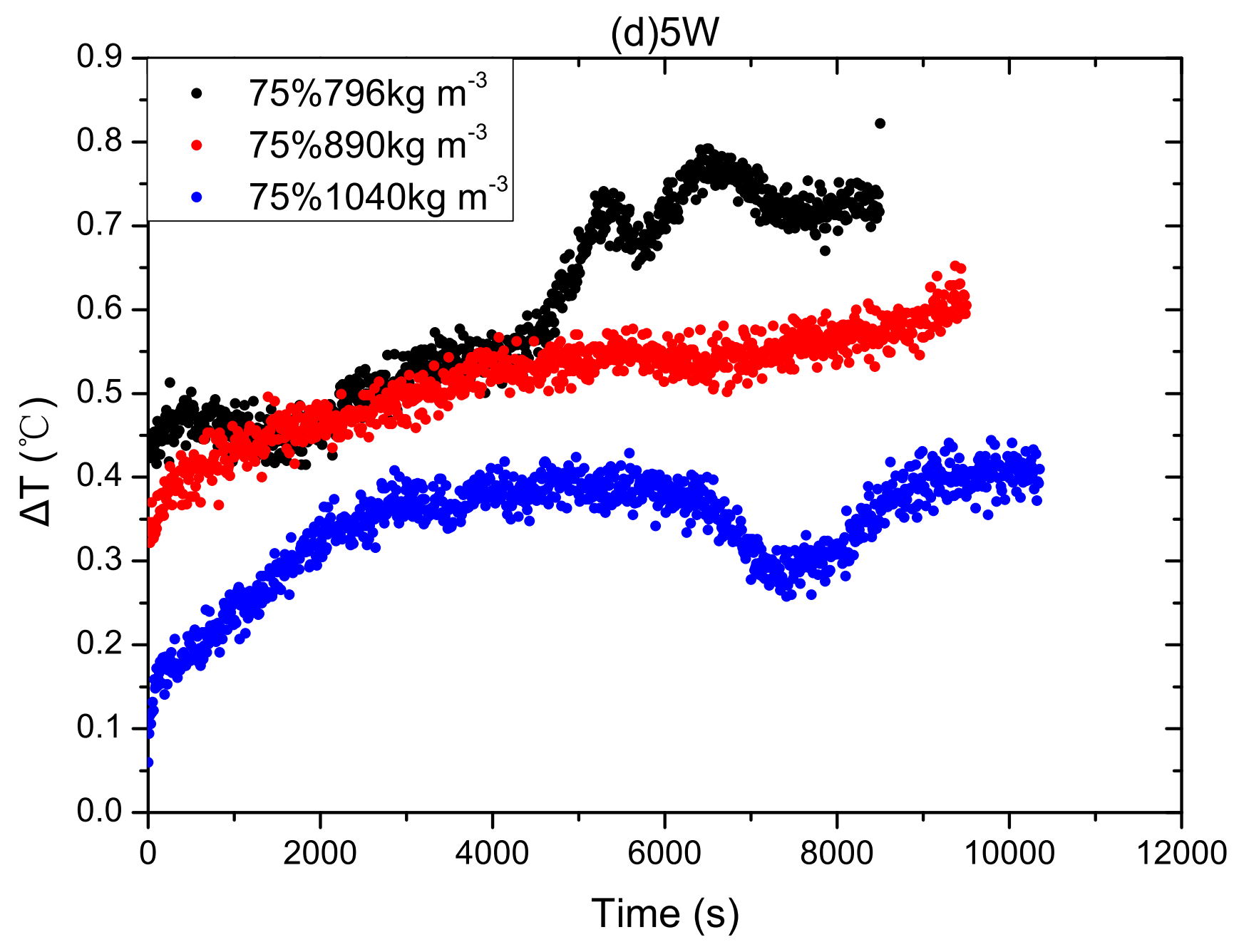




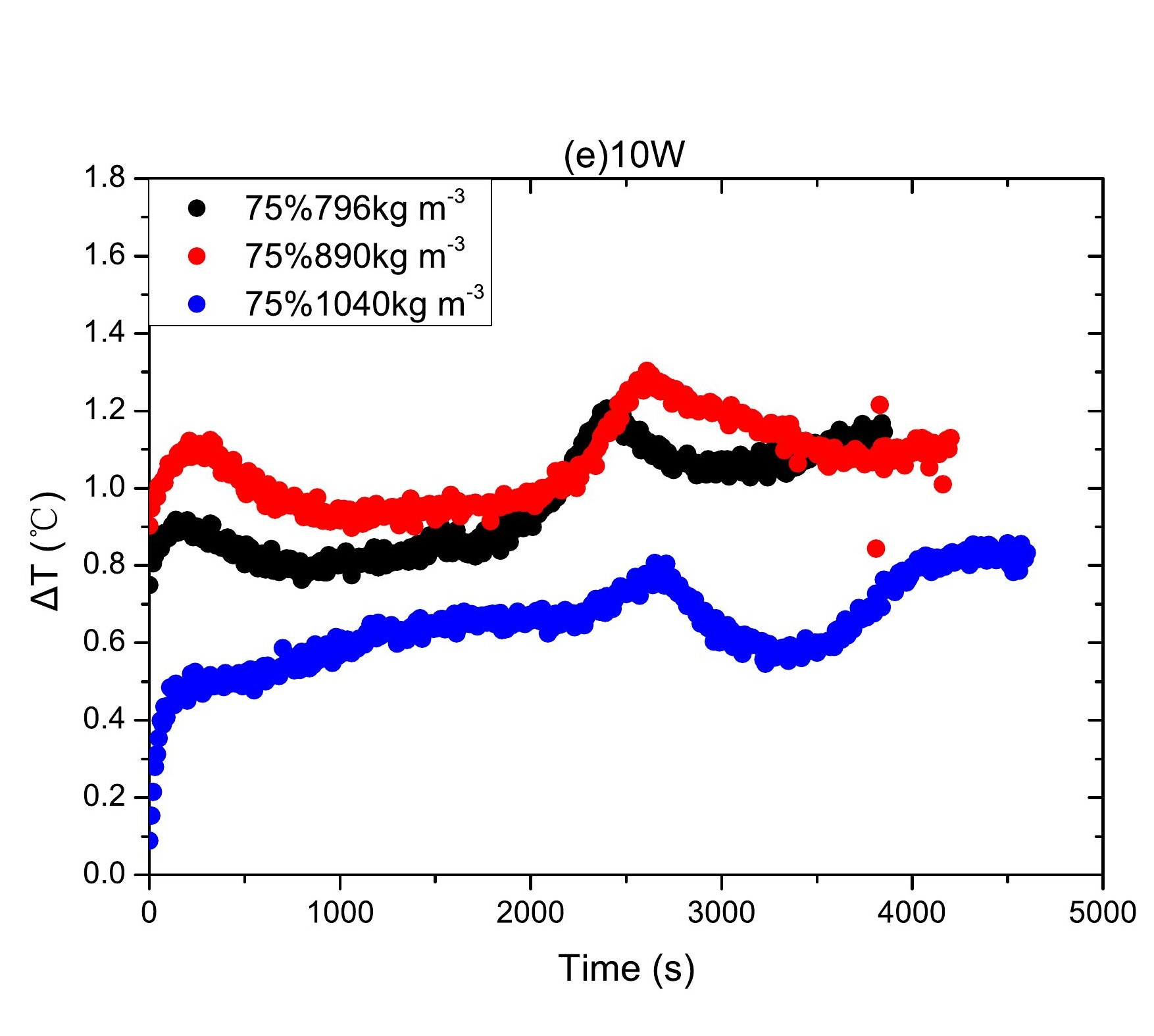

Figure $3 e$
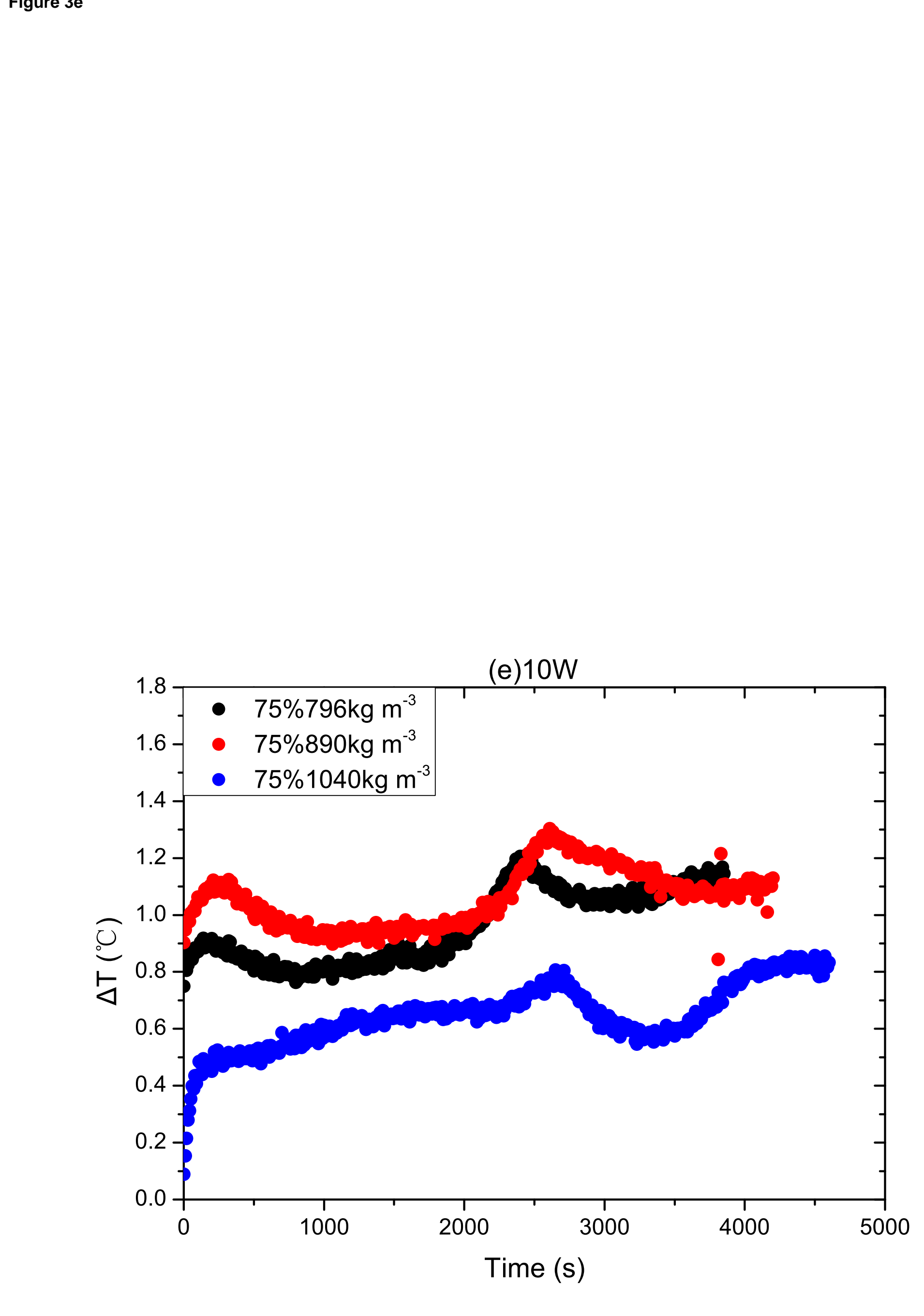


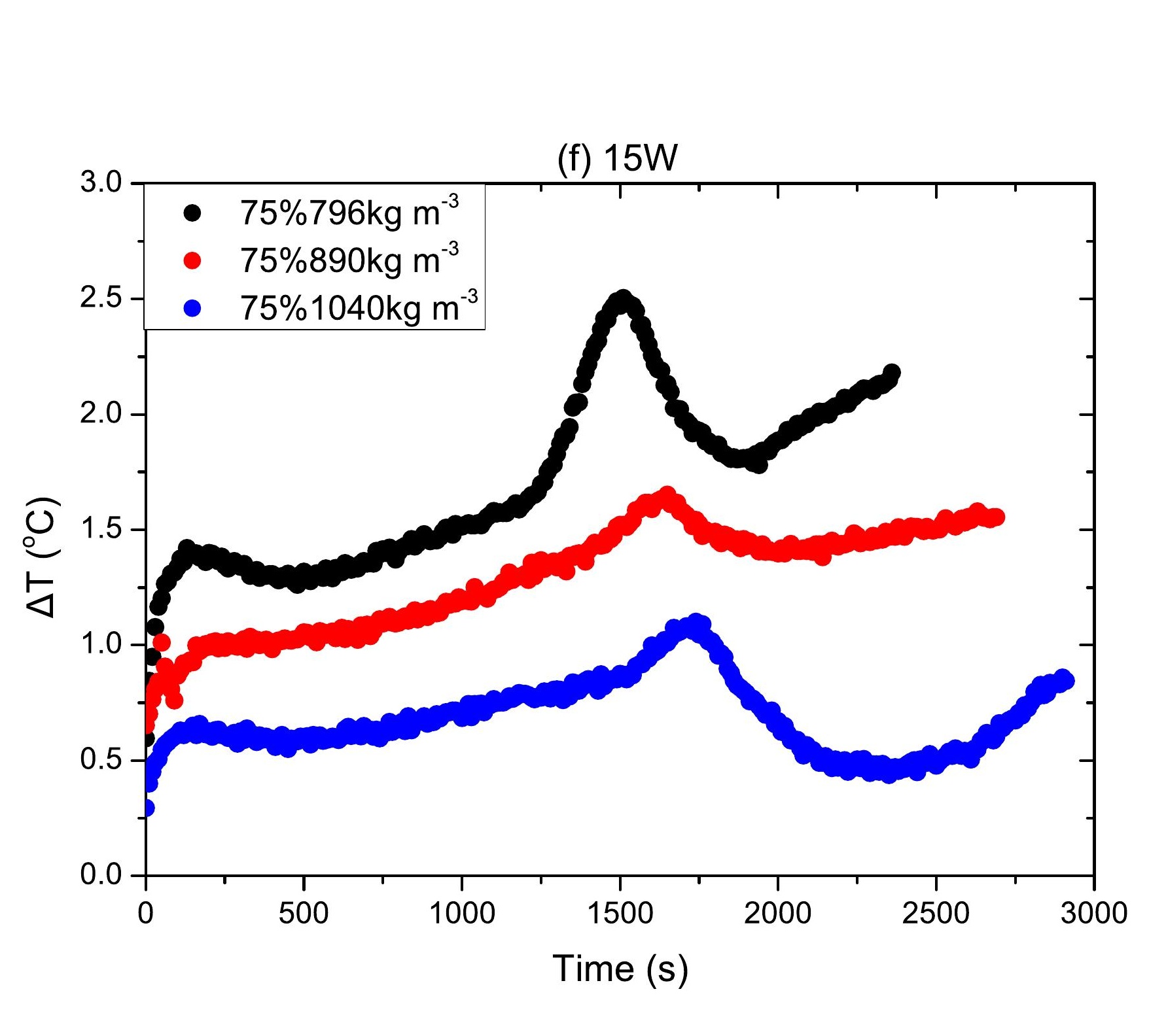

Figure $3 f$

\section{Figure $3 f$}

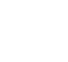

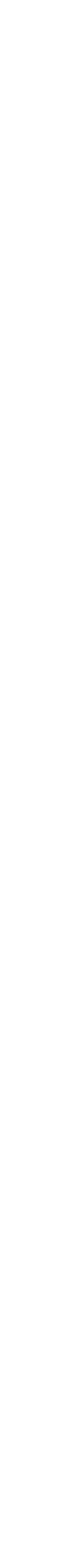

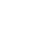
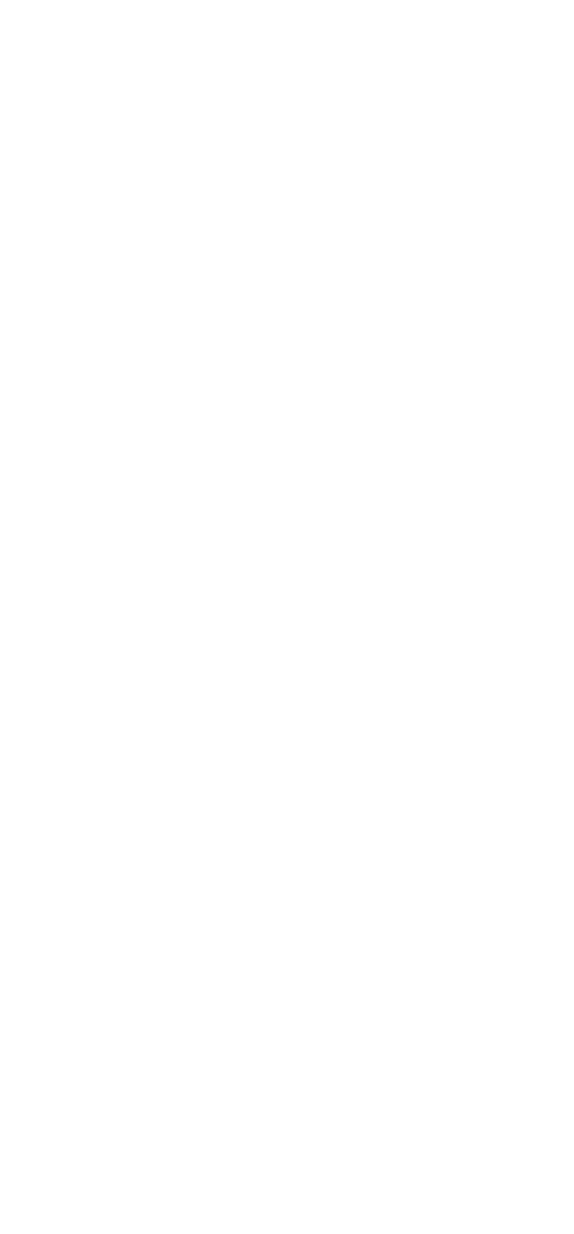


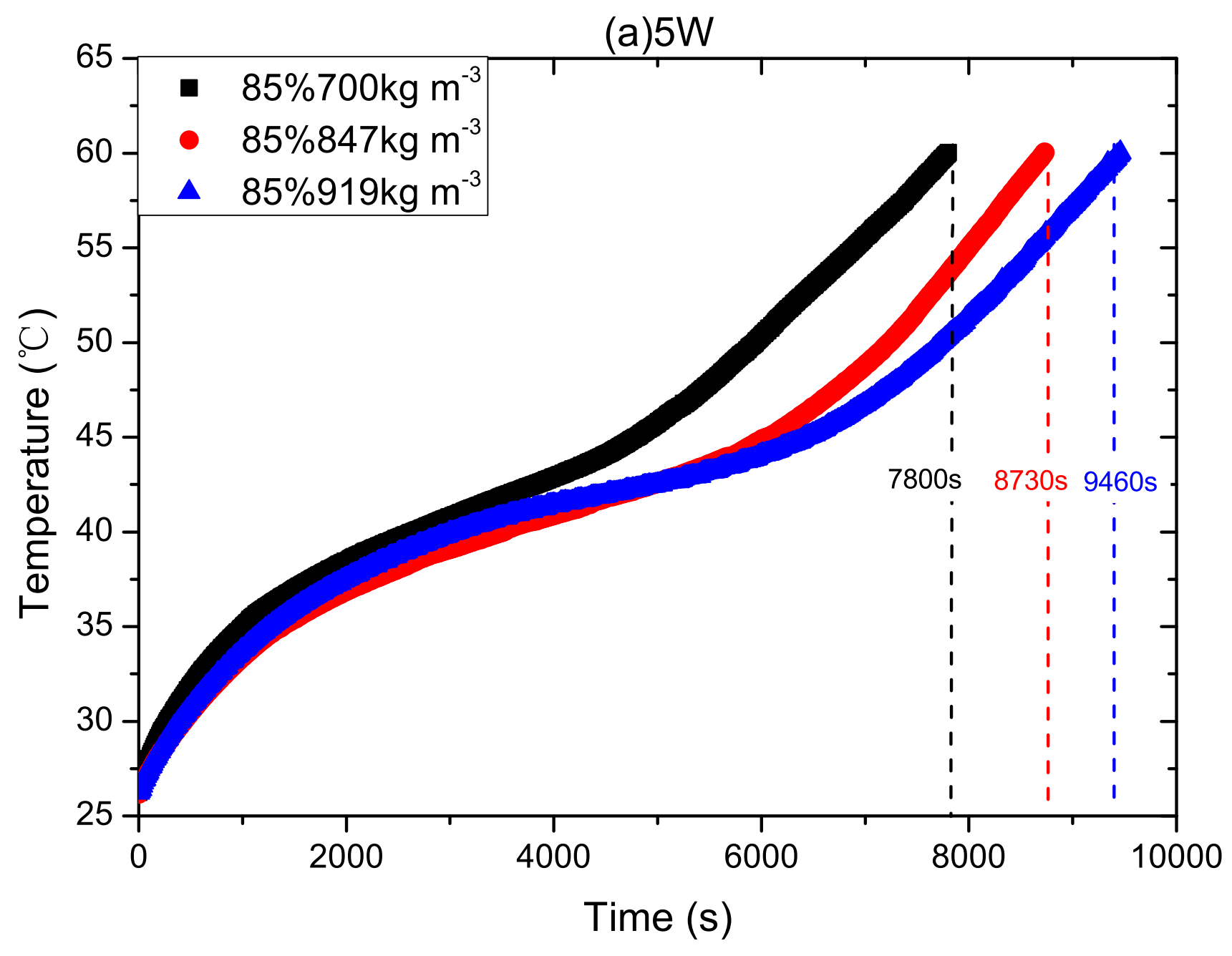




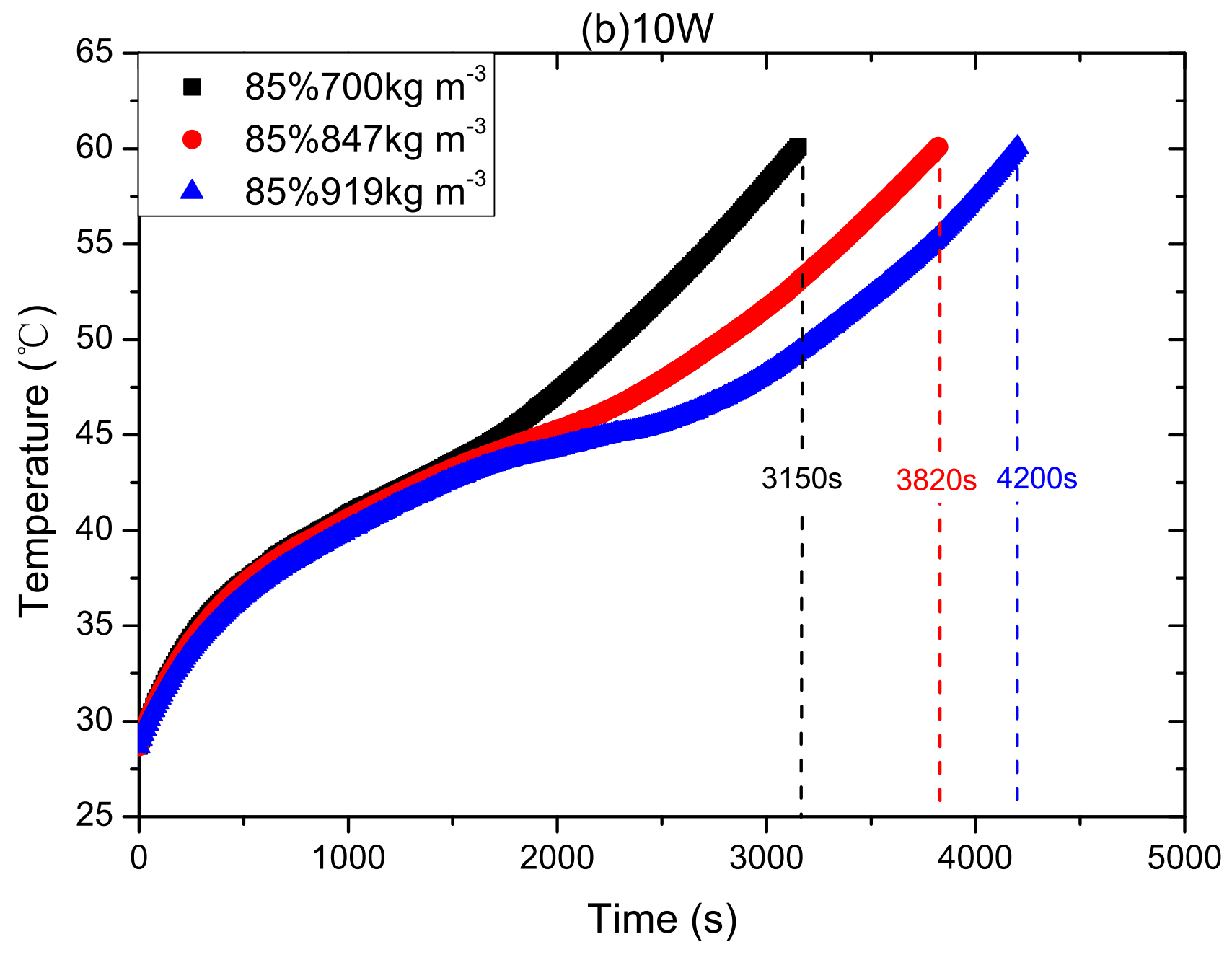




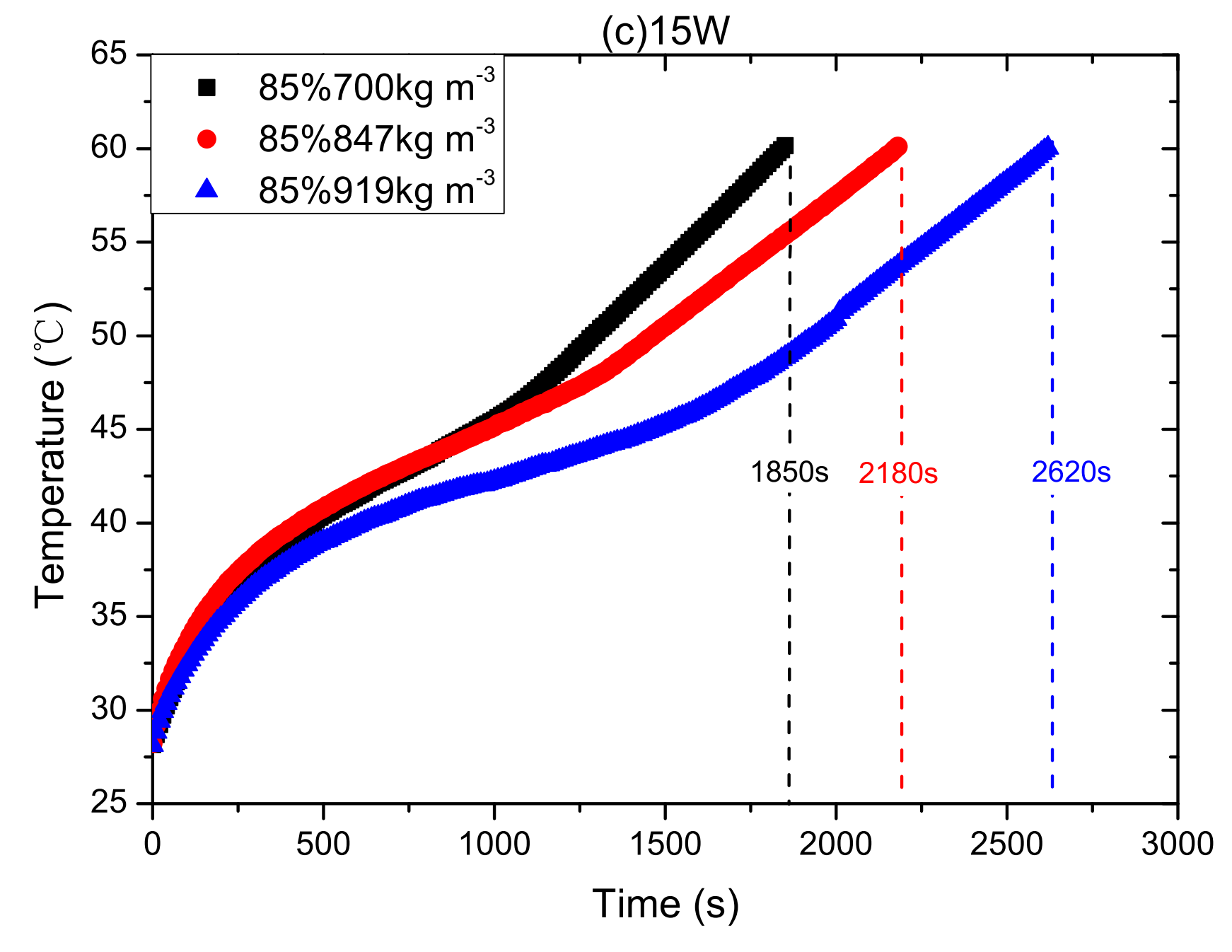

Figure 4c 


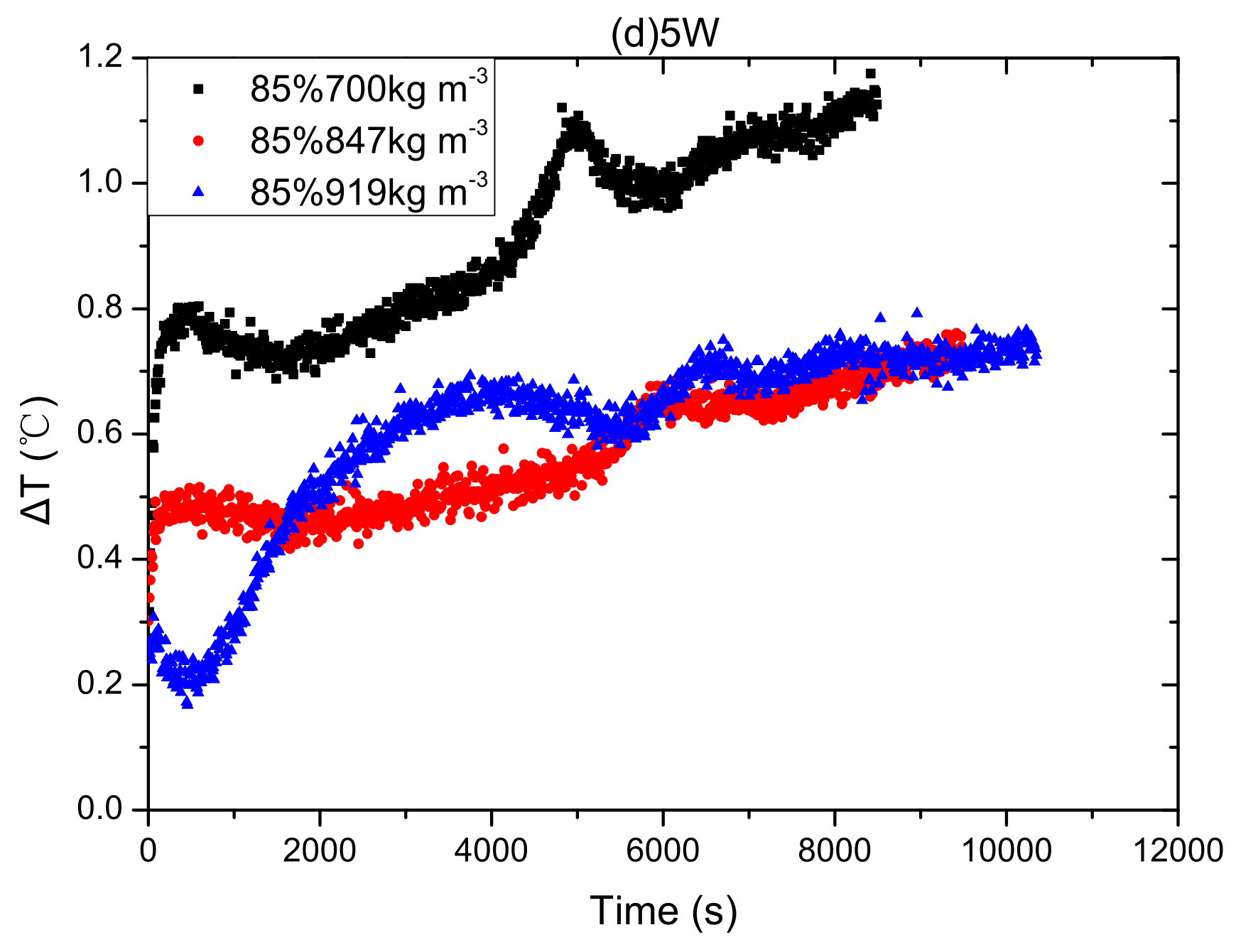

Figure 4d 


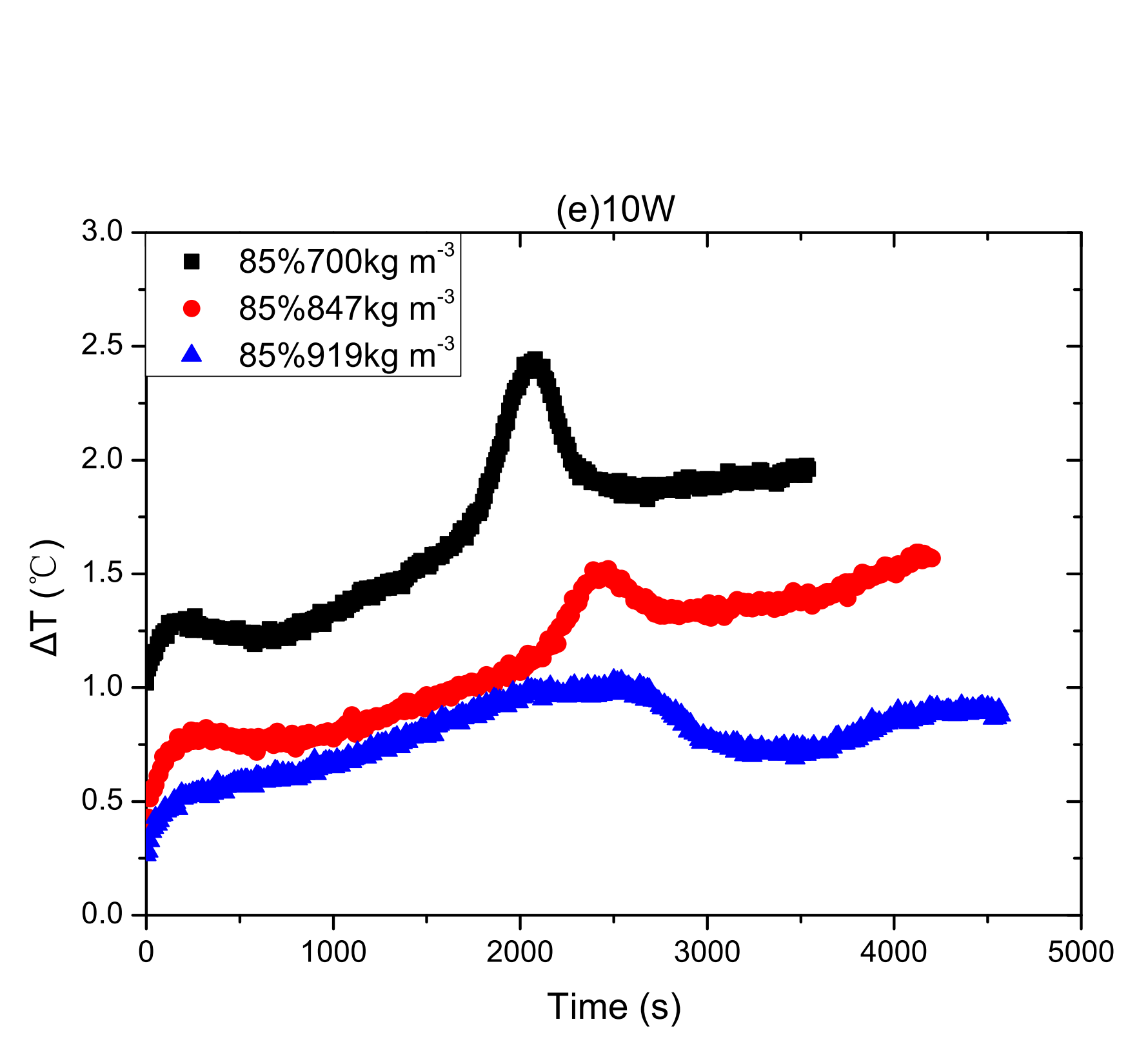

Figure $4 e$

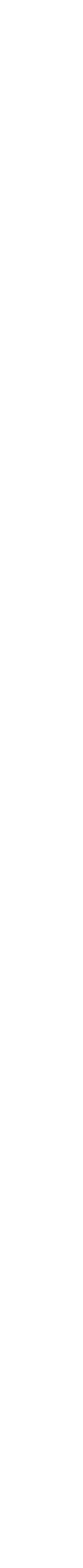

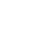
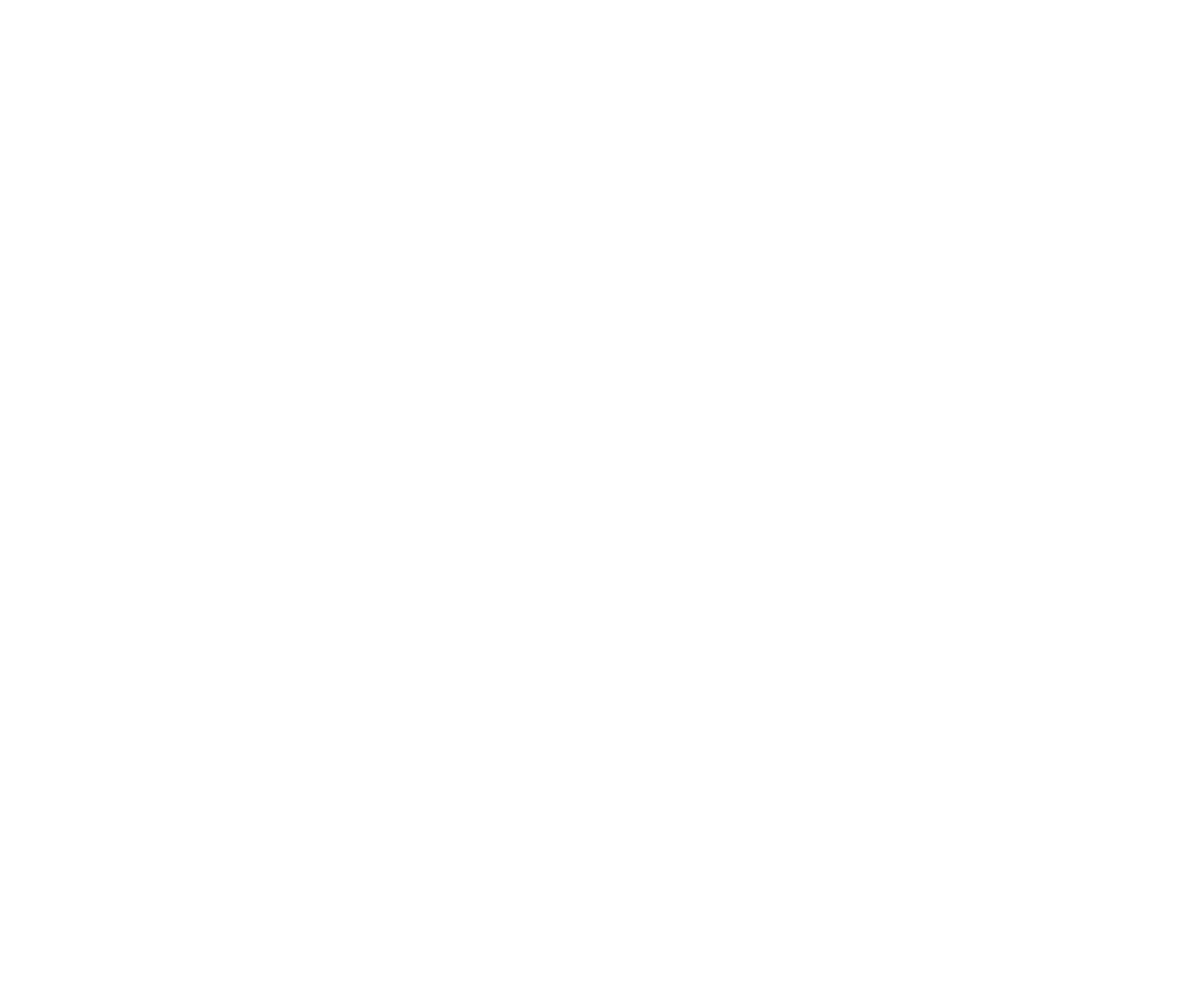


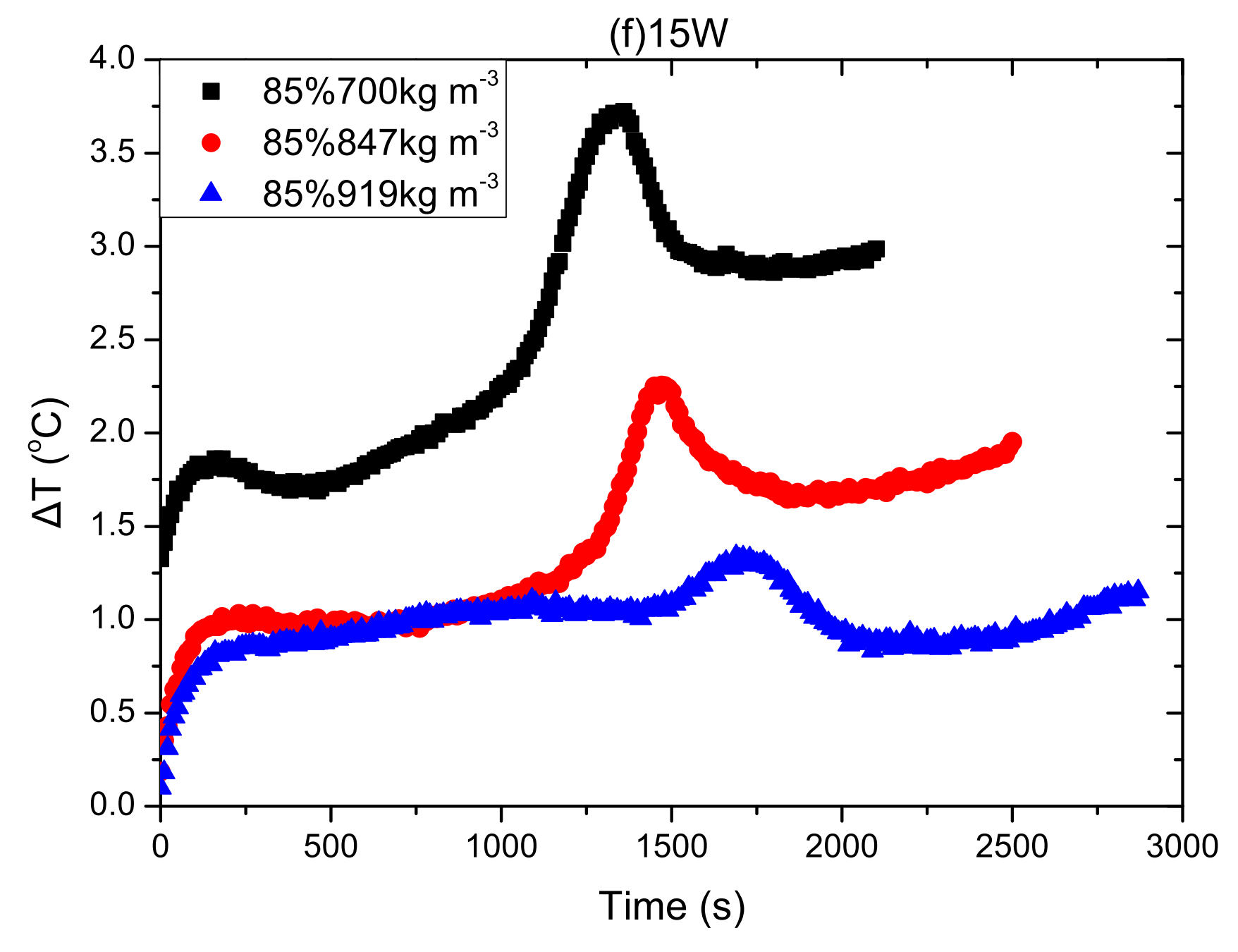

Figure $4 f$ 


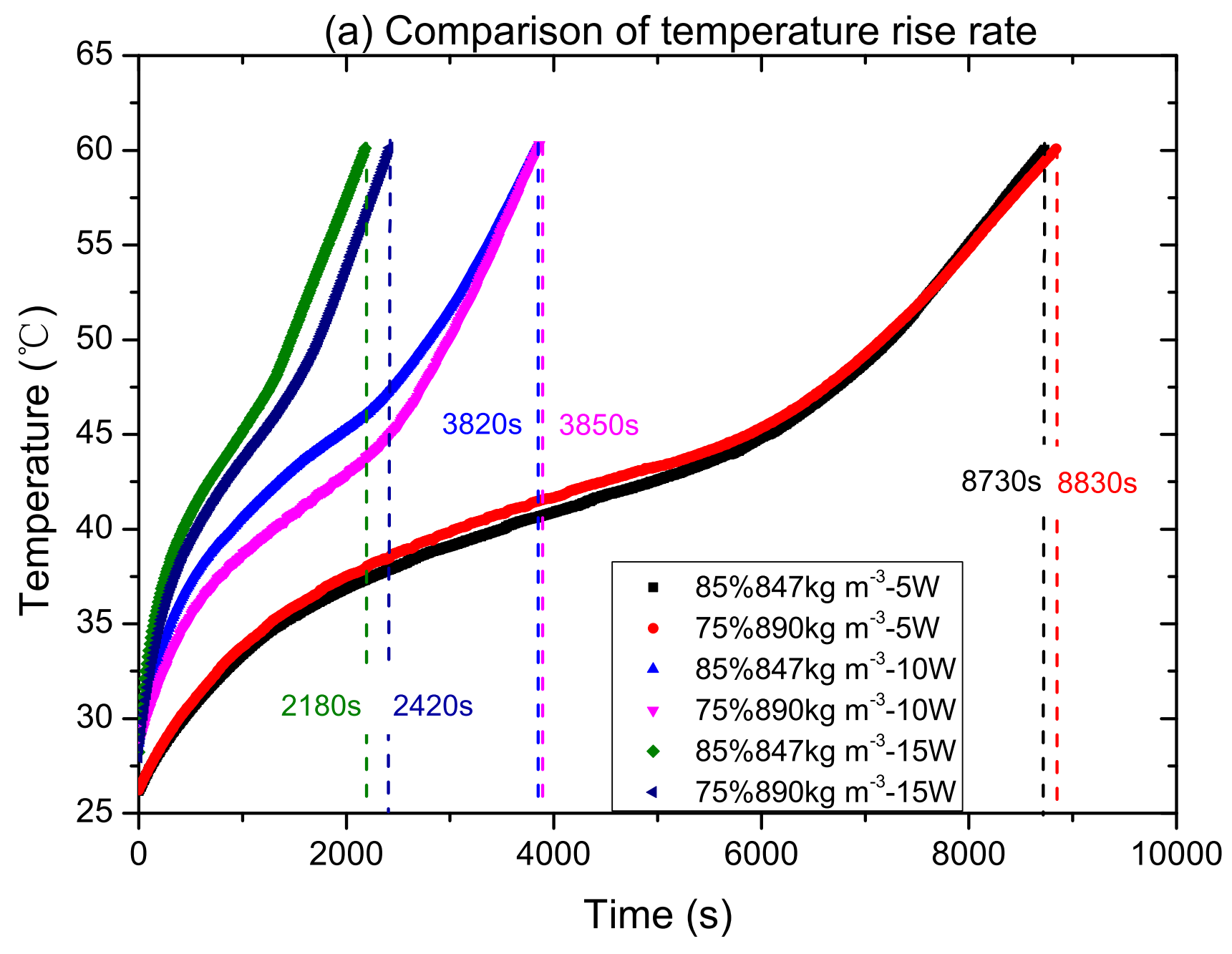




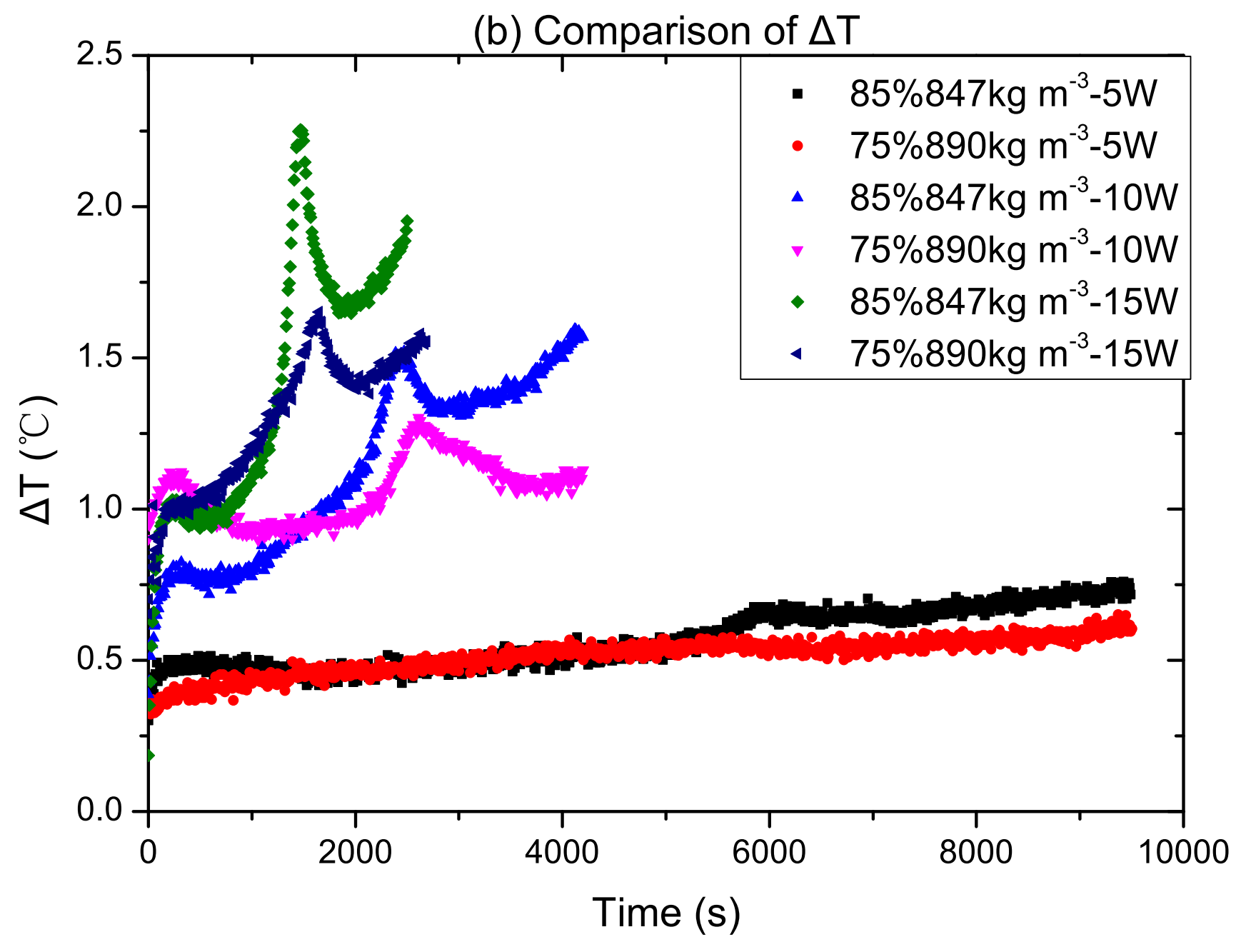




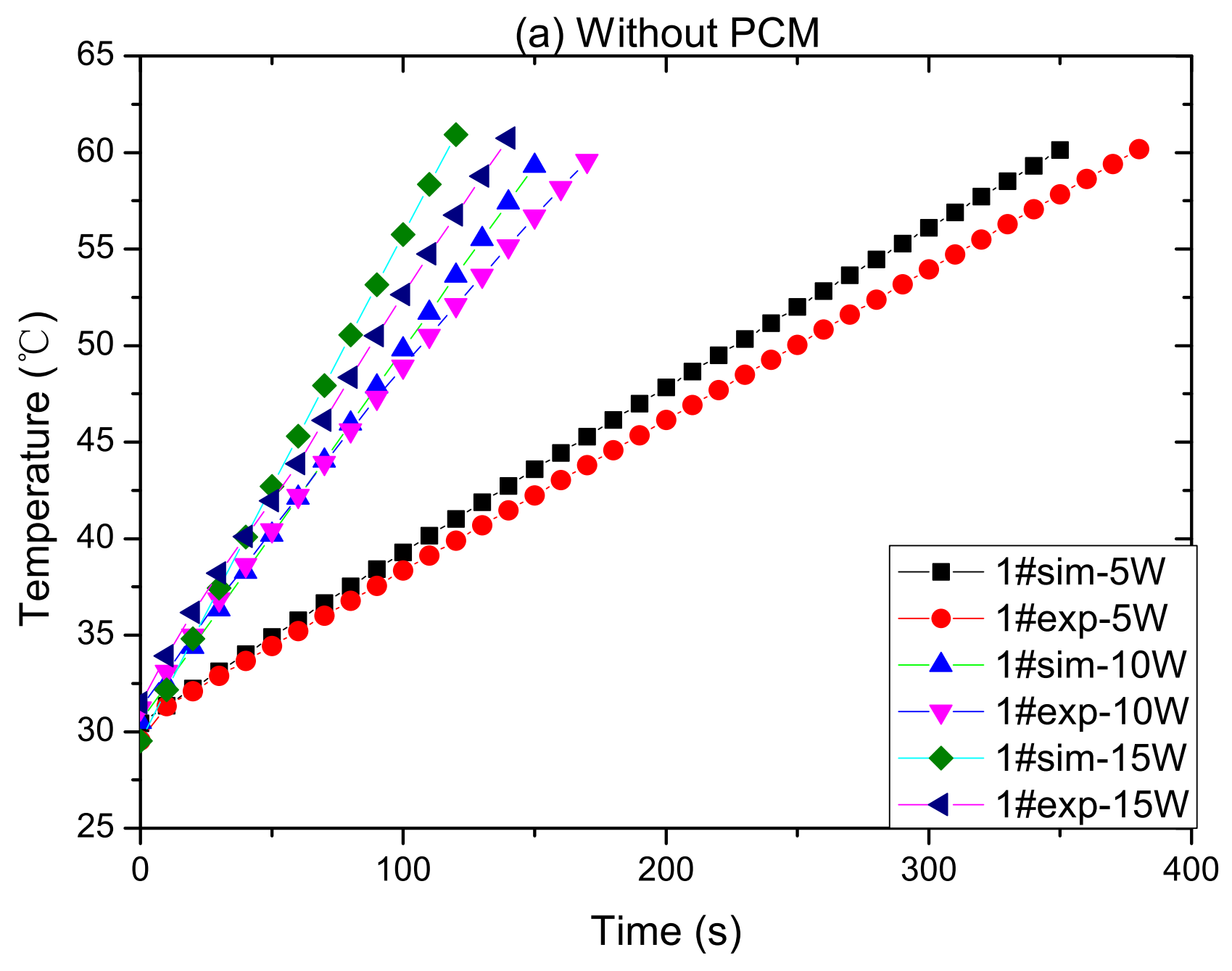




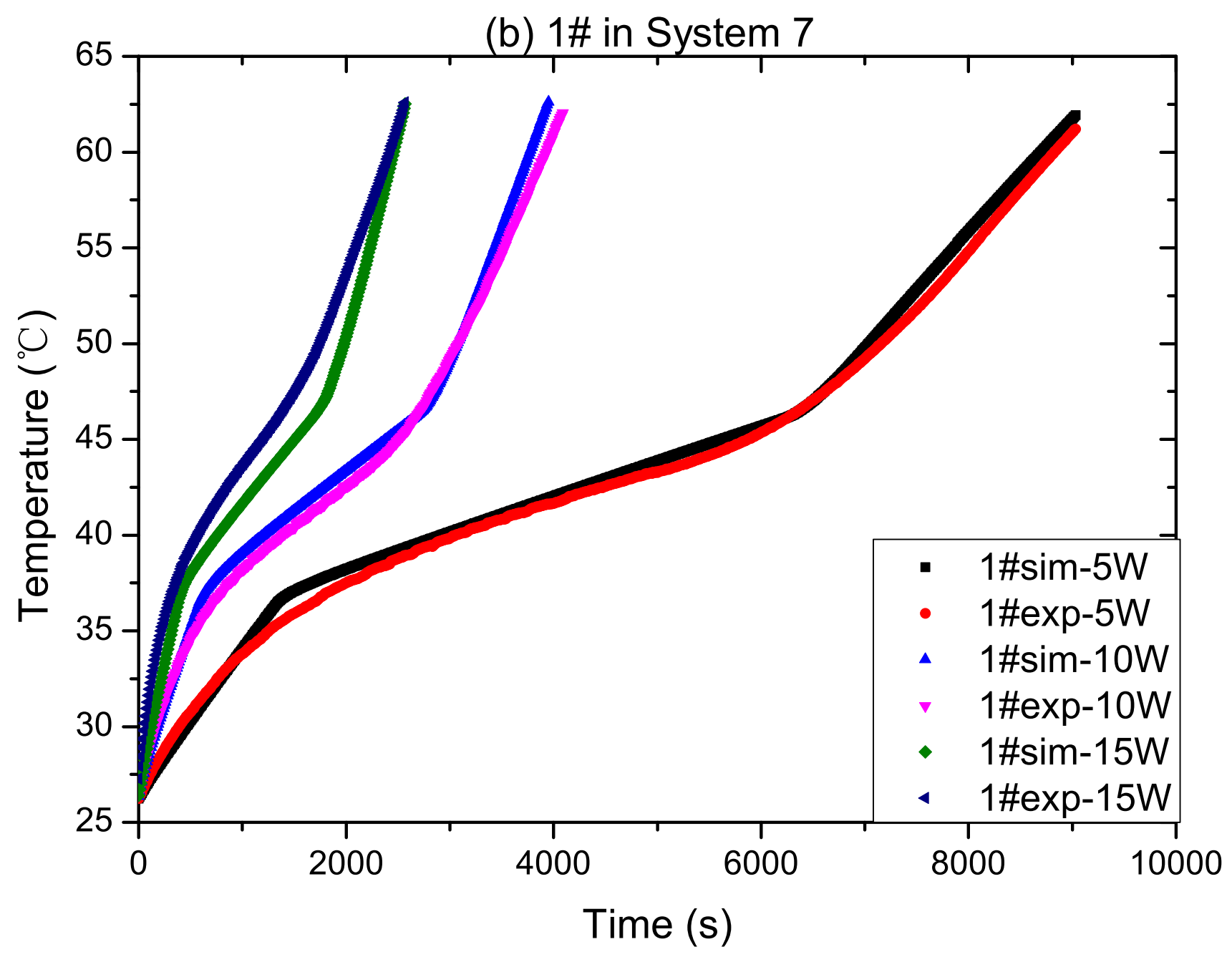




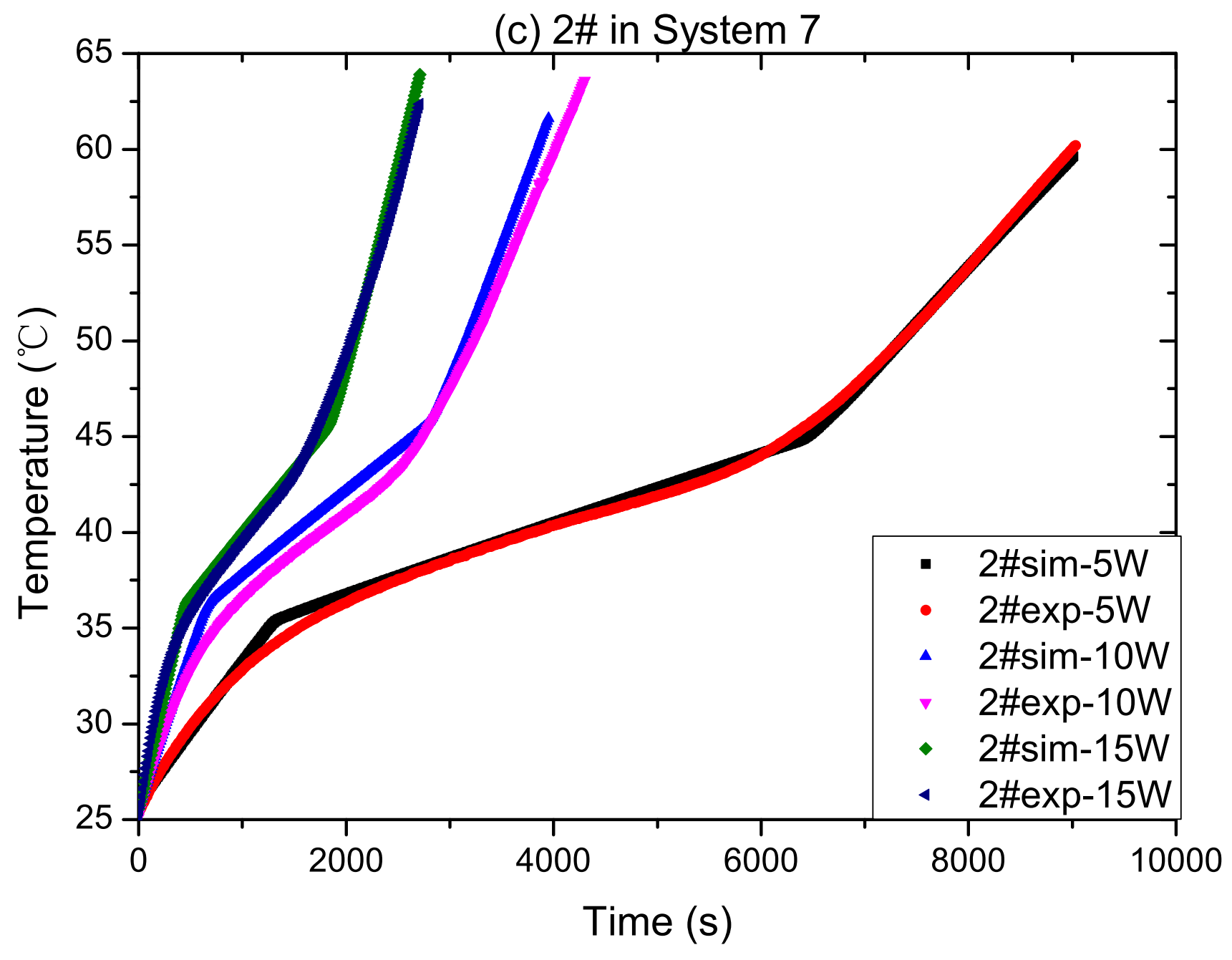


Table 1 Composition and thermo-physical properties of Paraffin/EG composite

\begin{tabular}{cccccccc}
\hline \multirow{2}{*}{ System } & \multicolumn{3}{c}{ Properties of paraffin/EG Composites } & \multicolumn{2}{c}{ System characteristics } \\
\cline { 2 - 7 } No. & $\begin{array}{c}\text { Melting } \\
\text { point }\left({ }^{\circ} \mathrm{C}\right)\end{array}$ & $\begin{array}{c}\text { Paraffin } \\
\text { mass } \\
\text { fraction }(\%)\end{array}$ & $\begin{array}{c}\text { Specific } \\
\text { enthalpy of } \\
\text { heat }\left(\mathrm{kJ} \mathrm{kg}^{-1}\right)\end{array}$ & $\begin{array}{c}\text { Specific heat } \\
\left(\mathrm{kJ} \mathrm{kg}^{-1} \mathrm{C}^{-1}\right)\end{array}$ & $\begin{array}{c}\text { Packing } \\
\text { density } \\
\left(\mathrm{kg} \mathrm{m}^{-3}\right)\end{array}$ & $\begin{array}{c}\text { Thermal } \\
\text { conductivity } \\
\left(\mathrm{W} \mathrm{m}^{-1} \mathrm{C}^{-1}\right)\end{array}$ & $\begin{array}{c}\text { Latent } \\
\text { heat } \\
(\mathrm{kJ})\end{array}$ \\
\hline $\mathbf{1}$ & 52 & $85 \%$ & 119.5 & 2.9 & 700 & 5.3 & 60.8 \\
$\mathbf{2}$ & 44 & $85 \%$ & 98.6 & 2.9 & 700 & 6.8 & 50.3 \\
$\mathbf{3}$ & 36 & $85 \%$ & 103.2 & 2.9 & 700 & 6.2 & 52.6 \\
$\mathbf{4}$ & 44 & $85 \%$ & 98.6 & 2.9 & 847 & 7.5 & 65.1 \\
$\mathbf{5}$ & 44 & $85 \%$ & 98.6 & 2.9 & 919 & 7.75 & 70.6 \\
$\mathbf{6}$ & 44 & $75 \%$ & 87.9 & 2.5 & 796 & 10.1 & 54.8 \\
$\mathbf{7}$ & 44 & $75 \%$ & 87.9 & 2.5 & 890 & 10.8 & 62.7 \\
\hline
\end{tabular}

